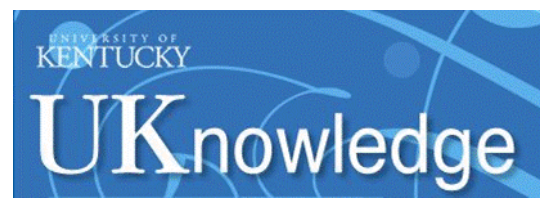

University of Kentucky

UKnowledge

\title{
ESCALATION AND REINSTATEMENT OF FENTANYL SELF- ADMINISTRATION IN MALE AND FEMALE RATS
}

\author{
Samantha G. Malone \\ University of Kentucky, samantha.g.malone@gmail.com \\ Author ORCID Identifier: \\ (iD) https://orcid.org/0000-0002-8498-4208 \\ Digital Object Identifier: https://doi.org/10.13023/etd.2020.421
}

Right click to open a feedback form in a new tab to let us know how this document benefits you.

\section{Recommended Citation}

Malone, Samantha G., "ESCALATION AND REINSTATEMENT OF FENTANYL SELF-ADMINISTRATION IN MALE AND FEMALE RATS" (2020). Theses and Dissertations--Psychology. 183.

https://uknowledge.uky.edu/psychology_etds/183

This Master's Thesis is brought to you for free and open access by the Psychology at UKnowledge. It has been accepted for inclusion in Theses and Dissertations--Psychology by an authorized administrator of UKnowledge. For more information, please contact UKnowledge@lsv.uky.edu. 


\section{STUDENT AGREEMENT:}

I represent that my thesis or dissertation and abstract are my original work. Proper attribution has been given to all outside sources. I understand that I am solely responsible for obtaining any needed copyright permissions. I have obtained needed written permission statement(s) from the owner(s) of each third-party copyrighted matter to be included in my work, allowing electronic distribution (if such use is not permitted by the fair use doctrine) which will be submitted to UKnowledge as Additional File.

I hereby grant to The University of Kentucky and its agents the irrevocable, non-exclusive, and royalty-free license to archive and make accessible my work in whole or in part in all forms of media, now or hereafter known. I agree that the document mentioned above may be made available immediately for worldwide access unless an embargo applies.

I retain all other ownership rights to the copyright of my work. I also retain the right to use in future works (such as articles or books) all or part of my work. I understand that I am free to register the copyright to my work.

\section{REVIEW, APPROVAL AND ACCEPTANCE}

The document mentioned above has been reviewed and accepted by the student's advisor, on behalf of the advisory committee, and by the Director of Graduate Studies (DGS), on behalf of the program; we verify that this is the final, approved version of the student's thesis including all changes required by the advisory committee. The undersigned agree to abide by the statements above.

Samantha G. Malone, Student

Dr. Michael T. Bardo, Major Professor

Dr. Mark Fillmore, Director of Graduate Studies 


\section{ESCALATION AND REINSTATEMENT OF FENTANYL SELF-ADMINISTRATION IN MALE AND FEMALE RATS}

\section{THESIS}

A thesis submitted in partial fulfillment of the requirements for the degree of Master of Science in the College of Arts and Science at the University of Kentucky

By

Samantha Gayle Malone

Lexington, Kentucky

Director: Dr. Michael T. Bardo, Professor of Psychology

Lexington, Kentucky

2020

Copyright (C) Samantha Gayle Malone 2020

https://orcid.org/0000-0002-8498-4208 


\section{ABSTRACT OF THESIS}

\section{ESCALATION AND REINSTATEMENT OF FENTANYL SELF-ADMINISTRATION IN MALE AND FEMALE RATS}

Escalation of intake and craving are two DSM-5 hallmark symptoms of opioid use disorder (OUD). Objectives: This study determined if escalation measured by long access (LgA) self-administration and craving measured by reinstatement are related. Adult male and female Sprague-Dawley rats were trained to self-administer (SA) fentanyl across 7 daily 1-h sessions, followed by $21 \mathrm{SA}$ sessions of either 1- or 6-h duration. Assignment to short access (ShA) and long access (LgA) groups was randomly determined for both males and females. Following 14 1-h extinction sessions, Experiment 1 assessed reinstatement induced by either fentanyl (10 or $30 \mu \mathrm{g} / \mathrm{kg}$ ) or yohimbine (1 or $2 \mathrm{mg} / \mathrm{kg}$ ), while Experiment 2 assessed reinstatement induced by a drug-associated cue light. Females acquired fentanyl SA faster than males and self-administered more than males throughout escalation. In extinction, compared to ShA rats, $\operatorname{LgA}$ rats initially responded less and showed less decay of responding across sessions. A fentanyl prime induced reinstatement, with LgA rats reinstating more than ShA rats at the $30 \mu \mathrm{g} / \mathrm{kg}$ dose; this effect of was specific to males. Yohimbine $(1 \mathrm{mg} / \mathrm{kg})$ also induced reinstatement, but there was no effect of access group or sex. With cue-induced reinstatement, LgA females responded less than LgA males and ShA females; the reduced fentanyl seeking to a cue in LgA females may reflect a general decrease in behavior, as this group also showed suppressed locomotor activity in a different context. Among the different reinstatement tests assessed, escalation of fentanyl SA in the LgA group increased only drug-primed reinstatement and only in males, suggesting a limited relationship between escalation of intake and craving (reinstatement) for OUD.

KEYWORDS: Escalation, Sex, Reinstatement, Cue, Yohimbine, Fentanyl

Samantha Gayle Malone

(Name of Student)

$10 / 01 / 2020$

Date 
ESCALATION AND REINSTATEMENT OF FENTANYL SELF-ADMINISTRATION IN MALE AND FEMALE RATS

\author{
By \\ Samantha Gayle Malone
}

Dr. Michael T. Bardo

Director of Thesis

Dr. Mark Fillmore

Director of Graduate Studies

$10 / 01 / 2020$

Date 


\section{DEDICATION}

To my grandparents: Tony Wade, Ida Anne Wade, and Cleo Wilkerson 


\section{ACKNOWLEDGMENTS}

I would like to express my sincere appreciation and gratitude for my advisor, Dr. Michael Bardo, and my committee members, Dr. Peggy Keller, Dr. Joshua Beckmann, and Dr. Pavel Ortinski, whose guidance and support have been invaluable in the development of this work. My deepest thanks go to Dr. Peggy Keller and Dr. Lindsey Hammerslag for putting in countless hours of meetings to improve my understanding of statistics and experimental design, and to Dr. Lynda Sharrett-Field for encouraging my passion to teach. Their patience, kindness, and dedication to my training has contributed heavily to my growth over the past two years. I am also thankful for our lab manger, Emily Denehy, our post-doctoral scholar, Dr. Cassie Chandler, and all the undergraduate researchers that contributed to this work. Their time and dedication to the production and execution of this project is greatly appreciated. I would also like to thank all other educators that have built upon my knowledge over the years. They have given me many tools that I will use and carry with me for the rest of my life.

Some contributions, however, are not as tangible as those above. I am extremely grateful to my parents, Ricky and Tony Malone, for their infinite love and support. This appreciation extends to my grandparents, Tony Wade, Ida Anne Wade, and Cleo Wilkerson. Their excitement for my personal growth inspires me daily. Also, thanks to Adam Foshie, for being an incredible shoulder to lean on and source of consolation throughout this process. Finally, thanks to my cousins Douglas and Logan Babb, my cat Special Boy, and my wonderful friends Caleb Bailey, Julia Jagielo-Miller, and Anita Adams for their radiant joy, humor, and comfort. All these individuals have made a lasting impact on my life and I continue to lead by their example. 


\section{TABLE OF CONTENTS}

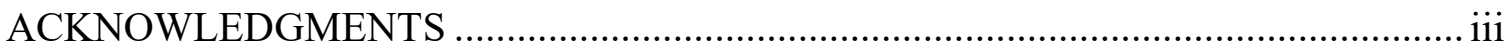

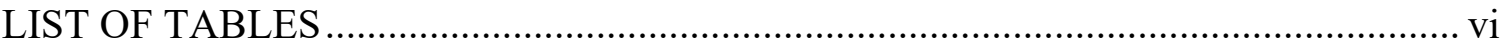

LIST OF FIGURES ……....................................................................................... vii

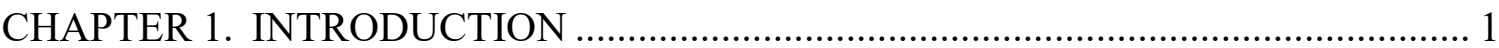

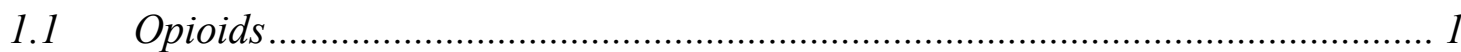

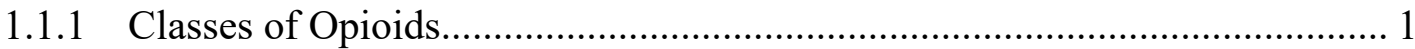

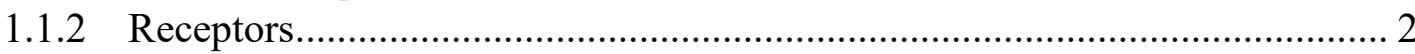

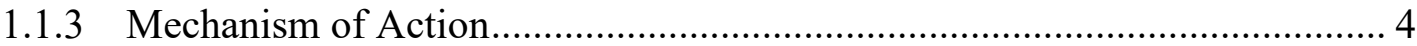

1.1.4 Abuse Liability and Risk Factors for Abuse................................................. 6

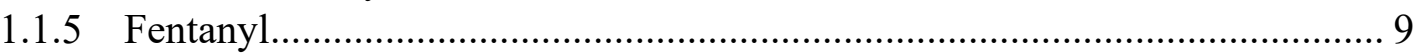

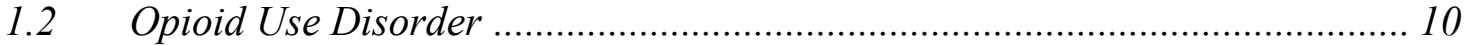

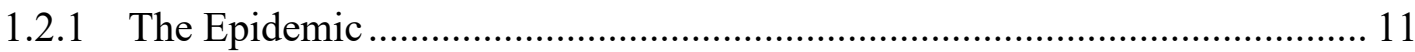

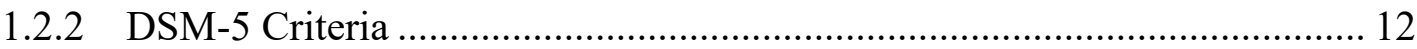

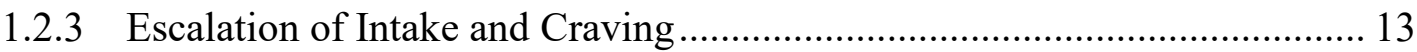

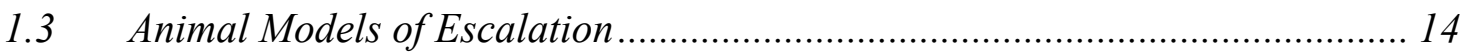

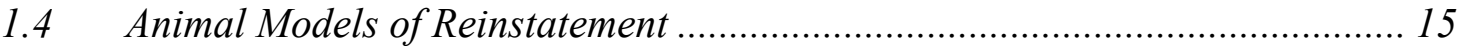

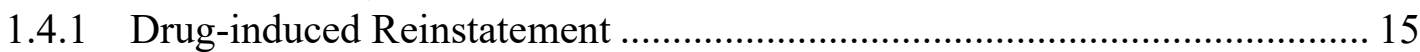

1.4.2 Stress- and Yohinmbine-induced Reinstatement ......................................... 16

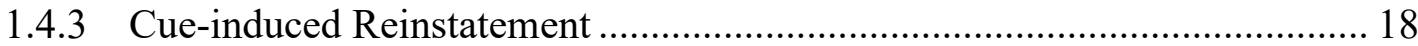

1.4.4 Limitations of Animal Models of Reinstatement.......................................... 19

1.5 Sex Differences in Opioid Use Disorder ..................................................... 21

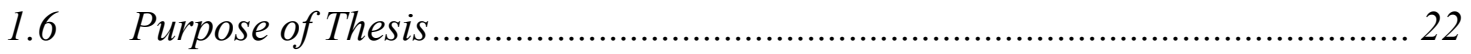

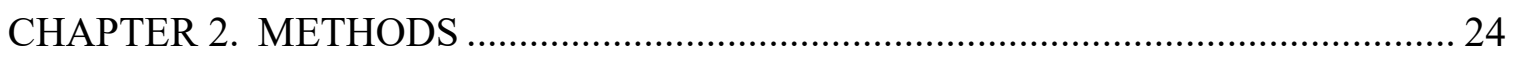

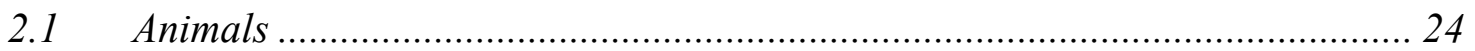

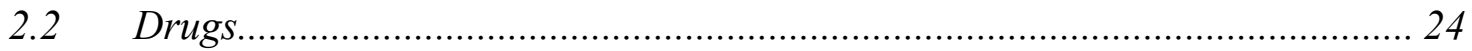

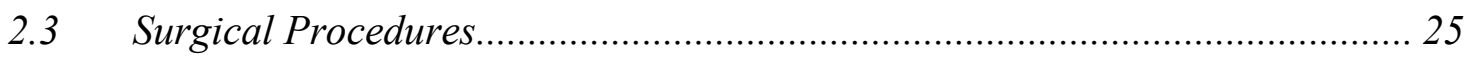

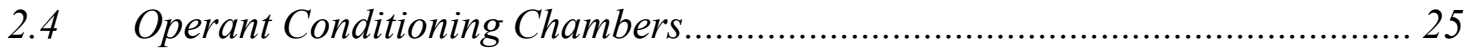

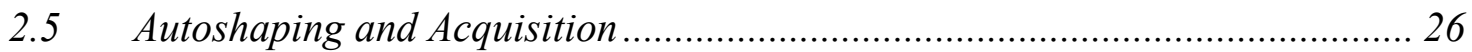

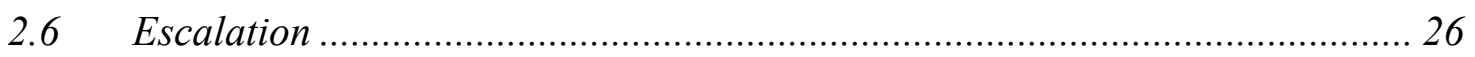

$2.7 \quad$ Estrus Cycle Testing ............................................................................ 27 
2.8 Experiment 1: Fentanyl-and Yohimbine-induced Reinstatement ................... 27

2.9 Experiment 2: Cue-induced Reinstatement and Locomotor Activity............... 28

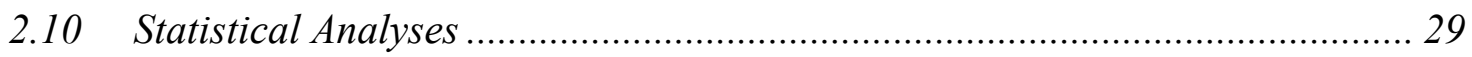

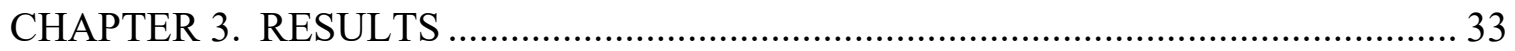

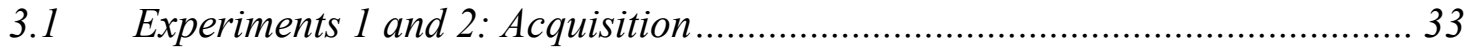

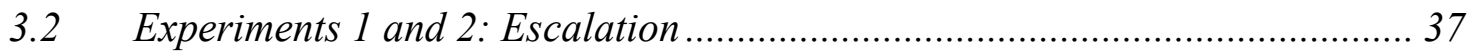

3.2.1 Results of Model Using Complete Data ................................................... 37

3.2.2 Results of Model Using Only the First Hour of Data Per Session ............... 41

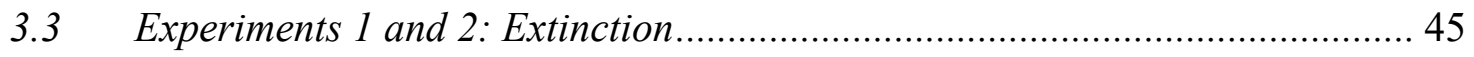

3.4 Experiment 1: Fentanyl-induced Reinstatement ........................................ 52

3.5 Experiment 1: Yohimbine-induced Reinstatement .......................................... 56

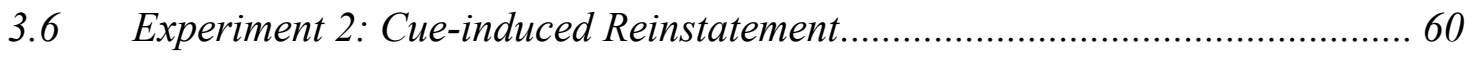

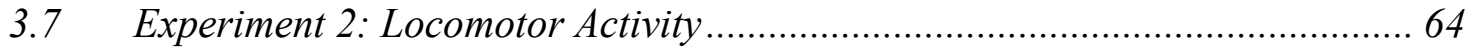

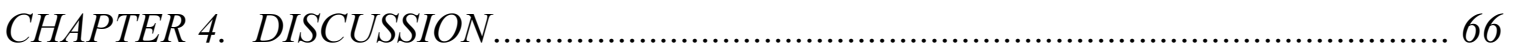

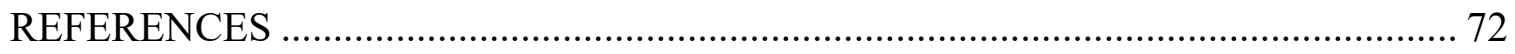

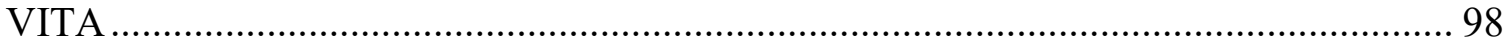




\section{LIST OF TABLES}

Table 2.10.1: Preferred model results for acquisition, escalation, and

Table 2.10.2: Preferred model results for reinstatement data...................... 32

Table 3.1.1: Model results for acquisition collapsed across Experiments

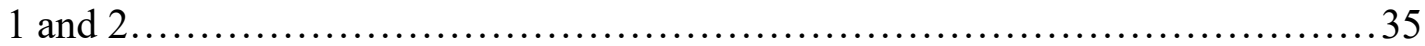

Table 3.2.1.1: Model results for escalation collapsed across Experiments

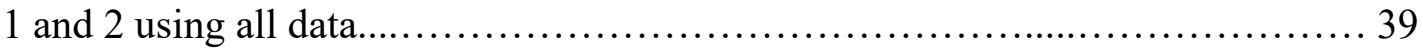

Table 3.2.2.1: Model results for escalation collapsed across Experiments 1 and 2 using the first hour of each session..................................... 43

Table 3.3.1: Model results for extinction in Experiment 1 with cue light

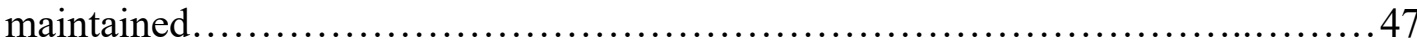

Table 3.3.2: Model results for extinction in Experiment 2 with cue light omitted.................................................................... 50

Table 3.4.1: Model results for fentanyl-induced reinstatement in Experiment 1.... 54 Table 3.5.1: Model results for yohimbine-induced reinstatement in Experiment 1.. 58 Table 3.6.1: Model results for cue-induced reinstatement in Experiment 2.........62 


\section{LIST OF FIGURES}

Figure 3.1.1: Acquisition during the autoshaping procedure collapsed across

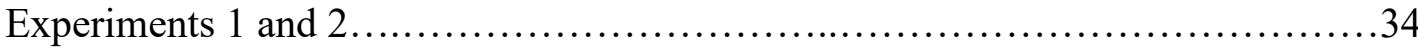

Figure 3.1.2: Preferred model for acquisition collapsed across Experiments 1

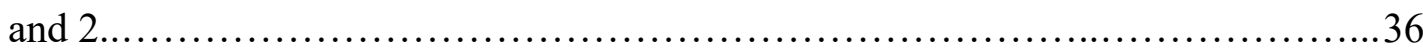

Figure 3.2.1.1: Escalation collapsed across Experiments 1 and 2 using all data......38

Figure 3.2.1.2: Preferred model for escalation collapsed across Experiments 1

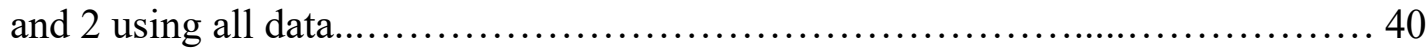

Figure 3.2.2.1: Escalation collapsed across Experiments 1 and 2 using the first hour of each session...................................................... 42

Figure 3.2.2.2: Preferred model for escalation collapsed across Experiments 1 and 2 using the first hour of each session........................................... 44

Figure 3.3.1: Extinction in Experiment 1 with cue light maintained.................46

Figure 3.3.2: Preferred model for extinction in Experiment 1 with cue light

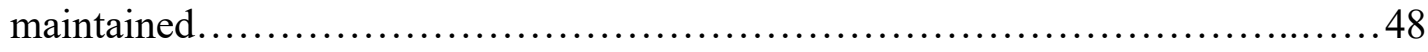

Figure 3.3.3: Extinction in Experiment 2 with cue light omitted.................... 49

Figure 3.3.4: Preferred model for extinction in Experiment 2 with cue light

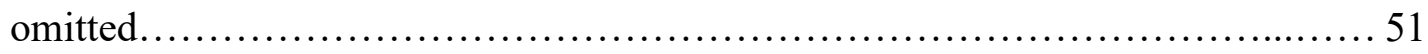

Figure 3.4.1: Fentanyl-induced reinstatement in Experiment 1...................53

Figure 3.4.2: Preferred model for fentanyl-induced reinstatement in

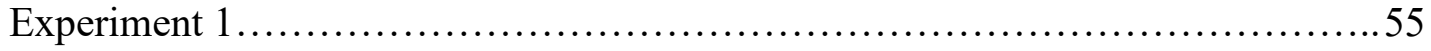

Figure 3.5.1: Yohimbine-induced reinstatement in Experiment 1.................57

Figure 3.5.2: Preferred model for yohimbine-induced reinstatement in

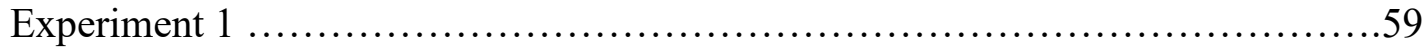

Figure 3.6.1: Cue-induced reinstatement in Experiment 2...................... 61

Figure 3.6.2: Preferred model for cue-induced reinstatement in Experiment 2..... 63

Figure 3.7.1: Locomotor activity $24-\mathrm{h}$ following cue-induced reinstatement test in Experiment 2. 


\section{CHAPTER 1. INTRODUCTION}

\section{$1.1 \quad$ Opioids}

Opioids are a category of chemically related substances that bind to and activate opioid receptors, primarily in the central and peripheral nervous systems, to produce a physiological effect (Merriam-Webster's Collegiate Dictionary, n.d.).

\subsubsection{Classes of Opioids}

There are four classes of opioids: (1) endogenous, (2) opium alkaloids, (3) semisynthetic, and (4) fully synthetic. Endogenous opioids are neuropeptides naturally produced in the body, primarily in the central nervous system. Some examples include enkephalins, nociceptins, endorphins, and dynorphins (Pathan \& Williams, 2012), which

are derivates of pro-enkephalin, pro-opiomelanocortin (POMC), and pro-dynorphin (McNally \& Akil, 2002). These precursor proteins are broken down into smaller peptides, which are further modified in post-translational processes and produces the endogenous opioid neuropeptides mentioned above (Froehlich, 1997). These endogenous opioids then play vital roles in multiple physiological functions, including stress, pain, respiration, gastrointestinal transit, immune, and endocrine regulation (Bodnar, 2013). Other opioid classes originate exogenously.

Opium alkaloids, such as morphine, codeine, and thebaine, are naturally derived from Papaver somniferum, the opium poppy plant. Opium alkaloids obtained from cultivating the opium poppy plant were utilized in multiple ancient cultures for food production, rituals, and medicine. Around the eighth century, Arab traders transported opium to China and India. Opium use quickly spread to the remainder of Asia and Europe 
around the tenth and thirteenth centuries. Manuscripts describing opium addiction in Egypt, Germany, England, and Turkey were found dated as early as the sixteenth century. Although China tried to subdue opium trade, British and French forces pressed China to appeal trade bans in the first and second opium wars, which ultimately led to more widespread opioid use (Brownstein, 1993). The modern era of opioids began in 1806 when Friedrich Sertürner isolated pure morphine from opium and boomed with the invention of the hypodermic syringe in 1853 for medical use as an analgesic for post-surgical pain (Blakemore \& White, 2002). These new innovations further promoted opioid abuse.

Soon, individuals began to search for less addictive alternatives to morphine and opium, and created the first semi-synthetic opioid, heroin, in 1898 (Brownstein, 1993). Semi-synthetic opioids, like heroin, hydromorphone, hydrocodone, and oxycodone, are all hybrids created chemically by altering natural opiates (Pathan \& Williams, 2012). Shortly afterwards, fully synthetic opioids such as meperidine, methadone, and fentanyl were synthesized in 1939, 1946, and 1960 respectively, for the same reason (Brownstein, 1993; Stanley, 1992). In contrast to semi-synthetic opioids, fully synthetic opioids are entirely chemically manufactured (Pathan \& Williams, 2012).

\subsubsection{Receptors}

All opioids act by binding to and activating G-protein coupled (GPCRs) opioid receptors. There are three primary opioid receptor subtypes that bind opioid ligands: $\delta$ receptors, $\mu$ receptors, and $\kappa$ receptors. These receptors are endogenously activated by enkephalins, endorphins, and dynorphins respectively, but may also be activated by exogenous opioids in the other opioid classes (Shang \& Filizola, 2015). A fourth opioidlike receptor, the nociception receptor, is related to these three opioid receptor subtypes, 
but shows little affinity for endogenous opioid peptides other than nociceptin (Pradhan et al., 2011; Butour et al., 1997). All opioid receptors are either Gi or Go protein coupled (Wolf, 2012).

Although these receptors differ slightly in function, they produce a comparable cellular response downstream following the binding of an opioid agonist. Each opioid receptor exchanges its $\alpha$ subunit guanosine diphosphate molecule (GDP) for a guanosine triphosphate (GTP). Following this exchange, the $\alpha$ subunit and GTP molecule separates from the beta gamma complex, allowing both structures to interact with proteins and inhibit adenylyl cyclase. This process often results in a decrease in cyclic adenosine monophosphate (cAMP) production, activation of potassium ion channels, inactivation of calcium ion channels, and hyperpolarization of the cell (Harrison et al., 1998; Corbett et al., 2006). In some cases, though, opioid receptor activation can result in heightened calcium influx (Pathan \& Williams, 2012). These receptors also interact with arrestins that are associated with GCPR endocytosis, desensitization, and kinase signaling (Bull et al., 2017).

Although $\delta$ receptor, $\mu$ receptor, and $\kappa$ receptor expression overlaps in most structures, some brain areas express more of one subtype over others. The $\delta$ opioid receptor subtype is heavily expressed in the neocortex, medial amygdala, and various olfactoryassociated brain areas. They are more selectively represented in the pontine nucleus of the cerebellum. The $\kappa$ opioid subtype is more abundant in the basal anterior forebrain but is the sole opioid receptor subtype expressed in multiple stress-associated areas such as the paraventricular nucleus, central amygdala, and pituitary gland. The $\mu$ opioid receptor subtype is more densely represented in the amygdala (excluding the central amygdala), 
thalamus, mesencephalon, and brain stem, but is also selectively expressed certain thalamic nuclei (Le Merrer et al., 2009). These three receptor subtypes are also expressed in peripheral areas such as the gastrointestinal tract, immune system, and heart, but to a lesser extent than in the central nervous system (Stein et al., 2003).

\subsubsection{Mechanism of Action}

In response to endogenous or exogenous opioids, opioid receptors produce an antinociceptive effect and alter how pain is perceived. Major portions of the descending pain pathway, including the dorsal horn of the spinal cord, rostral ventromedial medulla (RVM), and periaqueductal gray (PAG), express $\mu$ opioid receptors. Opioid receptors in this pathway regulate peripheral opioid-associated antinociception. Opioid binding to $\mu$ opioid receptors on GABAergic neurons in the PAG disinhibits RVM-projecting PAG neurons (Lueptow et al., 2018). This results in the excitation of dorsal horn projecting enkephalin and 5-hydroxytryptamine (5-HT) neurons (Pathan \& Williams, 2012), which is associated with inhibition of ascending pain signals, immense pain relief, and loss of sensation.

Opioids are also known to induce respiratory depression, which may be mediated by $\mu$ opioid receptors in certain brain stem locations (Dahan et al., 2018). The pre-Bötzinger complex in the medulla regulates respiratory rhythm and is critical to opioid-induced respiratory depression (Boom et al., 2012). The pre-Bötzinger complex also shows areas with $\mu$ opioid, neurokinin, and somatostatin receptor overlap (Ramirez, 2010). Evidence indicates that opioids target $\mu$ opioid receptors on neurokinin-1 receptor expressing neurons in the pre-Bötzinger complex. The inhibition of these neurons, via opioid receptor binding, is thought to cause the decreased respiratory rate associated with opioid administration. 
This area in the pre-Bötzinger complex expressing neurokinin-1 receptors appears more sensitive to the inhibitory effects of opioids and may be the primary respiratory mediating area associated with opioid-induced respiratory depression (Montandon et al., 2011). The reduction in respiratory rate and decrease in sensation combination resulting from opioid use produces a relaxing effect and may lead to unconsciousness, and ultimately to death.

The $\mu$ opioid receptor subtype is also associated with the reward pathway and is the primary target underlying opioid abuse. Morphine and other opioids of abuse bind to presynaptic $\mu$ opioid receptors on GABAergic ventral tegmental area (VTA) neurons. This results in a reduction of inhibitory tone on dopaminergic neurons targeting the striatum. Consequently, dopamine (DA) release in the striatum increases, which is associated with the rewarding, but not reinforcing, effects of opioids of abuse (Fields \& Margolis, 2015). Evidence indicates that knockout of the $\mu$ opioid receptor gene in mice prevents morphineinduced analgesia, decreases the rewarding effect of morphine, and lessens morphine withdrawal (Matthes et al., 1996). Also, $\mu$ opioid receptors in the amygdala may mediate reward-associated cue processing. Reward-directed behavior following a rewardpredictive cue decreases after $\mu$ opioid receptor inactivation but does not affect reward motivated behavior alone. This suggests that the role of $\mu$ opioid receptors in the amygdala may be vital to reward-associated cue recall for motivated behavior (Lichtenberg \& Wassum, 2017).

Less is known about $\delta$ receptors and $\kappa$ receptors in terms of behavioral pharmacology. While activation of $\kappa$ receptors tends to produce aversive effects, there is evidence that the receptor may be associated with the stress response and depression. Similarly, $\delta$ receptors may be involved in stress and depression, but additionally regulate 
pain and reward (Pradhan et al., 2011). This combination of effects produced by $\mu, \delta, \kappa$ and opioid receptor binding could produce an overdose, where individuals become unconscious with little to respiration and the risk of death is high (World Health Organization, 2018).

\subsubsection{Abuse Liability and Risk Factors for Abuse}

Considering the role of $\mu$ opioid receptors in the reward system, many opioids express high abuse liability. The rate of abuse for $\mu$ opioid receptor ligands, however, is dependent upon pharmacodynamics and pharmacokinetics. Pharmacokinetics determine how well the opioid ligand reaches and binds to the $\mu$ opioid receptor. The route of opioid administration can alter how well the administered opioid is absorbed into the bloodstream. Opioid bioavailability may decrease following some methods of opioid administration, such as oral and sublingual administration, by undergoing first pass liver metabolism. Other methods, such as intravenous injection, avoid first pass liver metabolism and allow opioids to reach the brain faster in higher concentrations (Stahl, 2008). Once opioids reach the brain via blood supply, they must cross the blood brain barrier (BBB). A lipophilic ligand with a low molecular weight may pass through the BBB using lipid-mediated free diffusion; however, highly lipophilic ligands are more likely to sequester in peripheral tissues, decreasing bioavailability (Pardridge, 2015; Banks, 2009). Heroin, for example, has a greater lipid solubility than morphine, which allows it to cross the BBB more easily. Although heroin is broken down into morphine after crossing the BBB, its ability to cross the BBB more efficiently than morphine makes it much more potent (Rutgers, 2018). Some opioids may be actively transported across the BBB or may utilize both passive diffusion and active transport. Evidence suggests that fentanyl uses both methods of transport, maximizing the amount of fentanyl crossing the BBB (Henthorn et al., 1999). Some ligands 
may pass through the BBB using passive aqueous diffusion; however, the molecule must have a small molecular weight (Stahl, 2008). Once an opioid ligand reaches the $\mu$ opioid receptor, the ligand's affinity determines how well it attracts to the receptor to bind and exert an effect. Opioids with a higher affinity for the $\mu$ opioid receptor typically express higher potency (Ellis et al., 2018). Fentanyl has one of the highest affinities for the $\mu$ opioid receptor (Trescot et al., 2008) and is highly potent.

The pharmacokinetics of $\mu$ opioid receptor ligands also vastly impacts the likelihood of opioid abuse. The efficacy of a $\mu$ opioid receptor ligand determines how well it produces the $\mu$ opioid receptor-mediated effects mentioned above. Opioids that act as full agonists at $\mu$ opioid receptors, such as morphine, heroin, fentanyl, and oxycodone, activate $\mu$ opioid receptors and initiate the downstream cellular effects associated with reward. Partial agonists, such as buprenorphine, bind to $\mu$ opioid receptors but display partial efficacy and a lower abuse potential compared to a full agonist (University of Arkansas Medical Center, 2020). Antagonists, such as naloxone, however, block $\mu$ opioid receptors and are often added to other opioids to decrease abuse liability (Comer et al., 2010).

The repeated administration of opioids and activation of $\mu$ opioid receptors may produce long-term changes in receptor regulation and neurocircuitry. These neural adaptations often manifest behaviorally as physical dependence and withdrawal in the absence of a $\mu$ opioid receptor agonist. Opioid withdrawal signs such as nausea, diarrhea, insomnia, autonomic hyperactivity, and piloerection are indicative of physical dependence (Shah \& Huecker, 2020). Withdrawal following opioid self-administration is aversive and removal of this aversive state by continued use acts as a negative reinforcer, which perpetuates the likelihood of continued opioid abuse (Koob, 2020; Thompson et al., 2012). 
The interplay between opioid pharmacodynamics and pharmacokinetic factors heavily influence their abuse liability.

Various environmental and biological factors contribute to the abuse liability of opioids at the individual level. Opioids are often prescribed following surgery, so discretion is needed when prescribing opioids as postsurgical care. Evidence suggests that a history of substance abuse, physical disabilities, previous mental health diagnoses, untreated psychiatric disorders and the prescription of some psychiatric medications are all predictors of opioid abuse following surgery in adults (Burcher et al., 2018; Klimas et al., 2019). Risk for opioid misuse is particularly higher in women with depression and men with somatization disorder (Manchikanti et al., 2007). Also, social environmental factors that encourage misuse similarly promote opioid abuse (McCarberg, 2015; Webster, 2017). Other factors that contribute to opioid dependence include: unemployment, post-traumatic stress disorder (PTSD), depression, anxiety, anti-sociality, trauma, younger age, substance abuse treatment, and co-use of psychotropic medication, alcohol, or illicit substances (Boscarino et al., 2010; Webster, 2017).

Genetics are another factor associated with a predisposition towards opioid abuse. Multiple dopamine-associated genes such as those coding the dopamine D2, D3, and D4 receptor subtypes, as well as the catecholamine enzyme catechol-O-methyltransferase (COMT), are linked to opioid abuse (Boscarino et al., 2010; Wang et al., 2019), and likely alter how opioids function in the reward system. Likewise, polymorphisms of opioid receptor genes and serotonin-associated mechanisms are correlated with opioid dependence and may promote abuse (Wang et al., 2019). Alterations in how opioids are degraded, however, may promote the adverse effects of certain opioids and decrease the 
likelihood of abuse. Evidence indicates that individuals with a certain polymorphism of the CYP2D6 enzyme gene may experience heightened adverse effects after administering codeine or tramadol (Haufroid \& Hantson, 2015). These are all potential factors that can influence the abuse liability of opioids at the societal and individual levels.

Opioids and other controlled substances are categorized into five schedules that reflect the potential for abuse, potential to develop dependence, and for potential medical use. These schedules are organized by the Drug Enforcement Agency (DEA) in the United States so that substances with a higher abuse liability fall closer to schedule I and substances with little to no abuse liability fall closer to schedule V. Most opioids are classified as schedule I or II, considering their high rate of abuse. Schedule I opioids, such as heroin, are considered to have no accepted medical use, a high abuse potential, and increased likelihood to develop dependence; whereas, schedule II opioids, such as morphine, may have a high abuse potential and increased likelihood to produce dependence, but show some medicinal use (DEA, 2020).

\subsubsection{Fentanyl}

Fentanyl is a schedule II, synthetic opioid with high abuse liability. Fentanyl's heightened lipid solubility increases its potency by maximizing its ability to cross the BBB. Once inside the brain, fentanyl acts as a full $\mu$ opioid receptor agonist and produces effects common to opioids such as respiratory depression, sedation, analgesia, and a feeling of reward. Considering fentanyl's high potency, a small amount of drug may produce a rapid rewarding effect; whereas, a large amount of a less potent opioid, such as morphine, may be necessary to produce an equivalent but potentially slower acting effect (DEA, 2019). In humans, the i.v. administration of fentanyl citrate distributes within 1.7 minutes and the 
elimination half-life ranges from 2-4 hours (Akorn Inc., 2017; El-Karamany, 2017); however, the elimination half-life of fentanyl varies from 2-27 hours dependent upon the route of administration and rate of absorption (El-Karamany, 2017). Cytochrome P450 (CYP450) metabolizes $99 \%$ of fentanyl into the inactive metabolite norfentanyl. The remaining $1 \%$ of fentanyl is metabolized to other inactive metabolites such as hydroxyfentanyl and despropionylfentanyl (DePriest et al., 2015; Smith, 2009). These properties of fentanyl inflate its abuse liability and likelihood of overdose following use.

Despite the high abuse potential of fentanyl, it is utilized medically as a reliever of severe pain and is consequently categorized as a schedule II substance (DEA, 2020). Prescription or casual illicit fentanyl use though, may quickly progress to fentanyl dependence and lead to overdose. While fentanyl alone is often abused, it is often combined, knowingly or unknowingly, with heroin or cocaine to produce a heightened euphoric effect, further promoting opioid associated overdose. Over 31,000 opioid associated overdose deaths were linked to synthetic opioids in 2018, which appeared to be a result of a rise in illicit fentanyl use (CDC, 2020). This places fentanyl use at the forefront of the opioid epidemic.

\subsection{Opioid Use Disorder}

Opioid use disorder (OUD) became a national concern when the rise in prescription opioid use resulted in a vast misuse of opioids and an 'epidemic' of opioid-associated overdose deaths. The introduction of illicit heroin and fentanyl further exacerbated the epidemic. Although OUD has become a rising issue, there are still some gray areas in the understanding of OUD and how certain symptoms may be related. 


\subsubsection{The Epidemic}

Opioid overdose deaths have been increasing exponentially over the past decade. In 2017 alone there were an estimated 47,600 opioid-related overdose deaths in the United States, a 12\% increase over the previous year (Scholl et al, 2019). Between 1999 and 2018, an estimated 450,000 people died of an opioid-associated overdose. The CDC reports there were three distinct waves of opioid use that led the United States to the current state in opioid overdose deaths (CDC, 2020). The first wave of the epidemic occurred following the increase in opioid prescriptions for pain relief in the 1990's. As the number of opioid prescriptions continued to increase, the number of opioid overdose deaths associated with prescription opioids continued to increase (CDC, 2011). In 2010, as prescription opioid overdose deaths began to plateau, there was there another wave of opioid overdose death associated with heroin (Rudd et al., 2014).

The third wave of opioid overdose deaths began more recently with the surge in synthetic opioid use. Of all opioid-associated overdose deaths in 2017, 59.8\% were caused by a synthetic opioid other than methadone, representing a $45.2 \%$ increase from 2016 to 2017 (Scholl et al., 2019). Beginning in 2013, illicit fentanyl became increasingly available (CDC, 2020), and use is rising significantly, especially in areas where more preventatives for prescription opioid use are in place (Fischer et al., 2020). Fentanyl is 100 times more potent than morphine, easily manufactured illicitly, and is frequently mixed with other substances of abuse, such as cocaine and heroin (CDC, 2019; Carroll et al., 2017; Klar et al., 2016). Multiple synthetic opioid-associated overdose deaths involved other substances which may be a result of drug mixing (CDC, 2020). These factors may allow users to easily obtain lethal doses and encourage the use of synthetic opioids, which may lead to 
worsening symptoms of opioid use disorder (OUD) and increase the likelihood of overdose.

\subsubsection{DSM-5 Criteria}

The DSM-5 defines opioid use disorder (OUD) as a chronic relapsing substance use disorder where intake escalates in both amount and duration, and users experience opioid craving, which often occurs during periods of abstinence and precipitates relapse (American Psychiatric Association, 2013). Considering the highly rewarding, positive reinforcing effect associated with use of opioids like fentanyl, misuse may rapidly develop into OUD and ultimately end in overdose. In fact, physical dependence may occur within 4-8 weeks (Sharma et al., 2016). The DSM-5 is used to establish common guideline for clinician diagnoses and describes OUD as a problematic pattern of behavior associated with opioid use, which may result in distress or conflict. There are eleven criteria listed in the DSM-5 that are associated with OUD and individuals must meet at least two of the descriptions within a 12-month period to fit an OUD diagnosis. Individuals with OUD may express an inability to fulfil work, school, or home responsibilities, may not participate in activities, and may use a vast amount of time to obtain, use, or recover from opioid use. Continuing opioid use despite frequent social, physical, or psychological problems and using them in potentially harmful situations are also indicators of OUD. Following an absence of opioid use, individuals with OUD may experience symptoms of withdrawal and use opioids to alleviate withdrawal symptoms (APA, 2013).

The current study outlined in this thesis places emphasis on the two key criteria mentioned in the DSM-5: (1) those with OUD may use opioids in large amounts and over a lengthy period, with little ability to control opioid intake, and (2) following a period of 
abstinence from opioids, users may experience a craving or desire, which promotes a return to drug-seeking (APA, 2013). Specifically, this preclinical study sought to determine if there is a relationship between these two criteria by assessing the escalation of intake with long-access self-administration sessions to model escalation (criterion 1) and by assessing reinstatement of fentanyl seeking following a period of extinction to model craving (criterion 2).

\subsubsection{Escalation of Intake and Craving}

While escalation of intake and relapse are often considered to be separate characteristics of OUD that may involve dissociable mechanisms, evidence suggests that intake amount may influence the propensity to relapse. While escalation and relapse have previously been considered unrelated and separate characteristics of OUD, evidence suggests that greater intake leads to increased risk of relapse (Smyth et al., 2010; Chalana et al., 2016). Similarly, a history of compulsive use and signs of dependence are associated with increased likelihood of relapse (Grau-Lopes et al., 2012). The level of use predicts success in outpatient treatment, where lower levels of lifetime and past-month intake correspond to improved outcomes for patients receiving buprenorphine maintenance treatment (Woodcock et al., 2015). There is also at least one preclinical study indicating that escalation of cocaine intake leads to increased drug-primed reinstatement in rats (Mantsch et al. 2004), suggesting that the mechanisms underlying escalation and reinstatement may overlap, at least in part. Thus, when examining relapse-like behavior in animal models it is critical to account for the dysregulated pattern of intake that is typical of humans with OUD. 


\subsection{Animal Models of Escalation}

There are a variety of animal models that simulate the escalation of intake; however, most current models utilize cocaine or other stimulant drugs. The escalation of cocaine intake can be achieved in rodents following 2-h self-administration sessions; however, extending the session length to 6-h results in greater escalated intake (Mandt et al., 2015). Rodents show poorer performance on a rodent equivalent of the Iowa Gambling Task 24-h following the escalation of cocaine intake and continue to perform worse one week later, suggesting that the escalation of cocaine intake may produce lasting changes and influence future behavior (Cocker et al., 2020). Escalated cocaine intake also occurs following intermittent access and may be more efficient in enhancing the incentive motivation for cocaine (Allain et al., 2018).

Fewer studies have examined the escalation of opioid intake. The escalation of opioid intake can be achieved with various opioids in rodent models using long-access selfadministration, where animals self-administer for session lengths of 6-h or longer (Wade et al., 2015). This pattern of escalated opioid intake seems to perpetuate withdrawal after drug removal. C57BL/6J mice escalate their intake of i.v. heroin when given 6-h access to self-administer heroin and show heightened symptoms of withdrawal after escalation (Towers et al., 2019). Rats given access to vaporized sufentanil for 12 -h per day similarly increase their intake across daily self-administration sessions and express heightened naloxone-precipitated signs of withdrawal compared to rats maintained on 1-h daily sessions (Vendruscolo et al., 2018). This demonstrates that there is a significant amount of progress in modeling the escalation of opioid intake and other potentially associated OUD symptoms; however, the impact of opioid escalation on relapse in animal models is largely unknown. 


\subsection{Animal Models of Reinstatement}

Relapse is modeled in laboratory animals using various paradigms designed to promote a return to drug-seeking behavior. Often, these procedures involve the use of rodents with indwelling venous catheters trained to self-administer a substance or rodents that have undergone conditioned place preference (CPP) for a specific drug of abuse. Following a period of extinction training, forced abstinence or voluntary abstinence, these methods may include the reintroduction of a drug or drug-associated cue, the introduction of a stressor, or administration of a different pharmacological substance other than the one previously self-administered. During this reinstatement period, the return to drug-seeking behavior is measured (Beardsley \& Shelton, 2012).

\subsubsection{Drug-induced Reinstatement}

The administration of an opioid after opioid self-administration or conditioned place preference (CPP) and extinction often results in reinstatement (Reiner et al., 2019). Morphine administration during CPP induces a preference for a single compartment in comparison to other compartments that can be extinguished and observed again when morphine is reintroduced (Khaleghzadeh-Ahangar \& Haghparast, 2015). The administration of heroin after extinction from heroin self-administration initiates a return to heroin-seeking. Also, rats exposed to both heroin and cocaine during self-administration will show drug-specific lever responding and reinstatement after the reintroduction of heroin or cocaine after extinction (Leri \& Stewart, 2001). The intracerebral injection of morphine into the VTA similarly produces reinstatement of morphine-seeking (Stewart, 1984), suggesting that lasting neural changes may occur following the self-administration of morphine. Heroin-induced reinstatement involves the $\mu$ opioid receptor, the dopamine 
D1 and D2 receptors, and perhaps cannabinoid receptors (Reiner et al., 2019, Fattore et al., 2011). It is likely that these reward-relevant receptors undergo changes during long-access (6-h) self-administration of opioid intake that does not occur during short-access (1-h). Further, drug-primed reinstatement of heroin seeking occurs in rats trained on extended (6h) access, but not in rats trained on short (1-h) access using the extinction/reinstatement paradigm (Lenoir \& Ahmed, 2007). However, it is not known if differences in short-access (ShA) vs long-access (LgA) self-administration also occur with stress- or cue-induced reinstatement, nor is it known if this effect generalizes to high potency opioids such as fentanyl.

\subsubsection{Stress- and Yohimbine-induced Reinstatement}

The hypothalamic-pituitary-adrenal (HPA) axis plays a key role in substance abuse and withdrawal. The HPA axis activates in response to acute administration of various substances of abuse and during withdrawal (Kreek \& Koob, 1998). In animal models, the acute administration of alcohol (Mendelson et al., 1971), nicotine (Kirschbaum et al., 1992), and cocaine (Heesch, 1995) all increase cortisol release through the HPA axis. The HPA axis appears to adapt after chronic nicotine exposure by increasing basal tone, resulting in more intense withdrawal during early abstinence (Wemm \& Sinha, 2019). This effect seems to be a result of nicotine's ability to activate the HPA axis by inducing the release of corticotrophin releasing factor (CRF) and norepinephrine in the paraventricular nucleus (PVN; Fu et al., 1997; Matta et al., 1990; Okada et al., 2003). Similarly, opioids appear to alter the HPA axis via changes in CRF regulation. Former heroin users on methadone maintenance express adrenocorticotropic hormone (ACTH) plasma levels equal to normal male volunteers after placebo but express significantly higher ACTH 
plasma levels after the administration of high-dose human CRF (Schluger et al., 2003). In rodents, i.c.v. infusion of a CRF2R antagonist during morphine withdrawal produces a decrease in somatic naloxone-induced withdrawal symptoms (Navarro-Zaragoza et al., 2011). In addition, i.c.v. injection of CRF augments reinstatement to heroin seeking and pre-treatment with a CRF antagonist attenuates footshock stress-induced reinstatement (Shaham et al., 1997). The changes in HPA axis and CRF regulation during opioid use likely trigger craving and relapse following stress in rodent models of OUD.

Stress-induced reinstatement typically involves the administration of a stressor following a period of extinction. Rats display a robust return to heroin seeking after exposure to a brief footshock stressor (Shaham \& Stewart, 1995; Shalev et al., 2000) or after 1-day food deprivation stress (Shalev et al., 2000). However, individual biological and behavioral factors may contribute to the propensity of stress-induced relapse to heroin seeking (Stafford et al., 2019). This effect also appears context specific. When footshock is performed in a drug-associated context, reinstatement to heroin seeking occurs. However, when footshock is performed in a novel context, the effect on heroin seeking is absent (Shalev et al., 2000). In mice, morphine CPP is reinstated after swim stress (Li et al., 2013; Ma et al., 2007), restraint, tail pinch, and social defeat stress (Riberio Do Couto et al., 2006). In contrast, acute food deprivation stress does not produce a reinstatement of morphine CPP (Ma et al., 2007).

There are also various pharmacological methods used to mimic stress-induced reinstatement of opioid seeking. This thesis study focuses on the pharmacological stressor yohimbine, an alpha-2 adrenoceptor autoreceptor antagonist that activates the sympathetic nervous system in humans and rodents to mimic stress and anxiety (Bremner et al., 1996a 
and b). The use of yohimbine as a pharmacological stressor has become more common because (1) it produces a robust return to drug seeking, (2) its reinstating effects can be blocked by CRF1 receptor antagonists, and (3) it can be used in both human and animal models of reinstatement (Mantsch et al., 2016). Yohimbine provokes a return to alcohol (Le et al., 1998), methamphetamine (Shepard et al., 2004), cocaine (Feltenstein \& See, 2006), and nicotine seeking in rats (Feltenstein et al., 2012). Yohimbine administration also reinstates food seeking behavior (Cifani et al., 2012). While little preclinical research has examined the reinstating effects of yohimbine on opioid seeking, clinical studies indicate that yohimbine produces anxiety-like symptoms and opioid seeking in opioiddependent patients on methadone maintenance (Stine et al., 2002) or buprenorphine maintenance (Greenwald et al., 2013). This study examined the reinstating effects of yohimbine after fentanyl escalation.

\subsubsection{Cue-induced Reinstatement}

In addition to context-induced reinstatement of drug seeking, cue-induced reinstatement promotes a return to drug seeking. In cue-induced reinstatement, animals are trained to self-administer a drug that is paired with a discrete cue (e.g., light, tone, scent). These cues become paired with drug intake across multiple self-administration sessions. During extinction, self-administration behavior dissipates when access to drug is removed with the concomitant removal of discrete or discriminate cues. Reinstatement is assessed when drug-associated cues are returned (Marchant et al., 2015; Shaham \& Nair, 2010; Reiner et al., 2019).

Exposure to a single discrete cue associated with drug taking promotes reinstatement to heroin seeking (Lai et al., 2013, Yue et al., 2014; Galaj et al., 2015; Smith 
\& Aston-Jones, 2012). This effect can be prevented by blocking certain DA receptors. Risperidone, a D2 and 5-HT2A antagonist, and 1-stepholidine, a dual D1 partial agonist and D2 antagonist, both attenuate cue-induced reinstatement to heroin seeking (Lai et al., 2013; Yue et al., 2014). Evidence also indicates that a D3 antagonist reduces heroin seeking following reintroduction of a heroin-associated cue (Galaj et al., 2015). Areas in the DA reward system, such as the NAc and prefrontal cortex (PFC), appear to regulate opioid seeking following cue-induced reinstatement. VTA or NAc microinjection of the sodium channel blocker tetrodotoxin prevents responding during extinction and heroin seeking behavior during cue-induced reinstatement (Zhou et al., 2007). Likewise, temporary inactivation of the mPFC using a muscimol and baclofen combination to block neural activity reduces cue-induced reinstatement of heroin seeking (Rogers et al., 2008). Perhaps, these areas undergo changes during the escalation of opioid intake, altering DA receptor regulation and susceptibility to cue-induced relapse. Following the escalation of fentanyl intake using intermittent access, but not long-access, male rats expressed greater cueinduced reinstatement compared to short-access (Fragale et al., 2020). Currently, no study examines the effect of escalation on cue-induced reinstatement on fentanyl seeking in rats.

\subsubsection{Limitations of Animal Models of Reinstatement}

Animal models of reinstatement have been criticized for their limited ability to model relapse in the human population (Epstein \& Preston, 2003). In particular, during the extinction period of the extinction/reinstatement model, animals are allowed to continue responding for saline. This does not directly parallel to the human condition, where individuals undergo self-imposed abstinence (Gardner, 2008), typically by choosing to remain abstinent even when drug may be available or by attending a rehabilitation facility 
to promote abstinence when the drug is not readily available; in neither case does the individual make a response for placebo. In addition, there are differences in the reinstatement portion of the extinction/reinstatement model. Experimenters may administer a drug prime to produce a return to drug seeking in animals, whereas humans self-administer the drug prime that precedes a full relapse (Marlatt, 1996). Similarly, with cue-induced reinstatement, experimenters may remove drug-associated cues during extinction in animals, whereas these drug-associated cues are not as easily removed in humans. For example, one study found that while handling money can trigger craving for heroin (Epstein et al., 2009), money is typically not removed from a recovering patient's environment. Considering the disparity between animal models of reinstatement and the characteristics of relapse in humans, more translational animal models of reinstatement should be explored.

Reinstatement models using forced or voluntary abstinence have attempted to better model the human condition by serving as analogues to human treatment in a rehabilitation facility or the continued choice to remain abstinent. In some forced abstinence models, instead of remaining in the drug-associated context, animals are relocated to a differing context with no drug or drug-associated cues available (Reichel \& Bevins, 2009). In voluntary abstinence models, animals remain in the drug-taking context but are presented with a choice between the drug and an alternative reinforcer such as palatable food or the chance to interact with a social peer. Under these conditions, animals will voluntarily refrain from drug taking even when drug is available (Venniro et al., 2019). Although these models may offer more appealing animal parallels to the conditions preceding human 
relapse, the current study was conducted with the extinction/reinstatement model of relapse because of the wealth of literature using this well-established method of reinstatement.

\subsection{Sex Differences in Opioid Use Disorder}

Males and females differ in performance on various assessments of OUD and show distinct patterns of opioid use. Generally, females acquire drug taking faster, escalate intake more rapidly, stabilize intake at higher doses, and relapse at a greater rate than males (Becker et al., 2017). Compared to men, women are more likely to use prescription opioids (Serdarevic et al., 2017); however, this difference in prescription opioid use may be explained by contrasting perceptions of pain. Women with comorbid chronic pain and opioid abuse reported heightened social and physical impairment associated with pain (Manubay et al., 2014). Although these patterns indicate women may be more vulnerable to opioid abuse, there is a greater incidence of abuse in the population for males (Becker \& Koob, 2016).

In rats, females acquire the self-administration of heroin faster than males (Lynch \& Carrol, 1999) and dose-dependently self-administer morphine and heroin at greater rates than males (Cicero et al., 2003). Females show greater self-administration than males on a FR5 schedule of reinforcement for 0.32 and $1 \mathrm{ug} / \mathrm{kg} /$ injection of fentanyl and show greater performance on a progressive ratio (PR) schedule for 3.2 and $10 \mathrm{ug} / \mathrm{kg} / \mathrm{injection}$ of fentanyl. This sex effect, however, is dependent upon schedule of reinforcement and reverses when males and females are given concurrent access to $3.2 \mathrm{ug} / \mathrm{kg} / \mathrm{injection}$ of fentanyl and 18\% diluted Ensure ${ }^{\circledR}$ (Townsend et al., 2019). On a progressive ratio schedule, where the number of responses required doubled with each infusion, females had a higher FR breaking point than males for morphine (Cicero et al., 2003). Furthermore, 
female mice escalate heroin intake at a faster rate than males across daily 6-h selfadministration sessions (Towers et al., 2019). Also, while evidence indicates that females are more vulnerable to the reinstatement of methamphetamine, cannabinoid, and cocaine seeking (Becker \& Koob, 2016), currently no study has examined the differences in males and female reinstatement following the escalation of fentanyl intake or reinstatement of fentanyl seeking in rats.

\subsection{Purpose of Thesis}

The purpose of the current study was to determine if there is a relation between escalation of opioid intake and relapse, as this would suggest a common underlying neural mechanism. Toward this goal, we used a preclinical model of escalated fentanyl selfadministration and reinstatement. While both escalation of opioid use and reinstatement of opioid seeking have been modeled in rats and mice, there have been no systematic studies to determine if there is a relation between these DSM-like characteristics of OUD. In one study, rats given access to vaporized sufentanil in long access (12-h) sessions showed escalated intake and expressed heightened naloxone-precipitated signs of withdrawal compared to rats maintained on 1-h daily sessions (Vendruscolo et al. 2018); however, propensity for relapse was not assessed. In the current study, to model escalation, we used a long access (6-h) schedule described previously (Wade et al. 2015; Towers et al. 2019). To model relapse, we used the extinction-reinstatement model with forced abstinence as described previously (De Vries et al. 1998; Shalev et al., 2002; Stairs et al. 2006). Reinstatement was assessed by either a drug prime or a pharmacological stressor (yohimbine), as well as by a fentanyl-associated cue. 
The second purpose of the current study was to determine if sex differences exist in the relation between escalation and relapse with fentanyl self-administration. In both humans and rats, escalation of drug intake and reinstatement of drug seeking are generally higher in females than in males (Becker, 2016), although much of this work has been conducted with stimulants. In the case of opioids, one study found that female C57BL/6J mice escalate heroin intake with long access (6-h) sessions more than male mice, at least when a low unit dose $(30 \mu \mathrm{g} / \mathrm{kg})$ is used (Towers et al. 2019). Based on this finding, we hypothesized that female rats would show greater escalation of fentanyl intake and greater reinstatement of fentanyl seeking compared to males. 


\section{CHAPTER 2. METHODS}

\section{$2.1 \quad$ Animals}

Male $(\mathrm{n}=34)$ and female $(\mathrm{n}=37)$ Sprague-Dawley rats from Envigo Laboratories (Indianapolis, IN) were delivered at 8-9 weeks of age and individually housed in a humidity- and temperature-controlled colony room maintained on a 12-h light/dark cycle (lights on at 0700-h). All animals had access to food and water ad libitum throughout the experiment. All rats were acquired and tested in cohorts of 12 or 24. All procedures were performed in accordance with the NIH Guide for the Care and Use of Laboratory Animals and were approved by the Institutional Animal Care and Use Committee (University of Kentucky).

\subsection{Drugs}

Fentanyl $\mathrm{HCl}$ was acquired from the National Institute on Drug Abuse (NIDA Drug Supply Program, Rockville, MD) was dissolved in $0.9 \%$ bacteriostatic saline to make the doses used in the study for self-administration $(2.5 \mu \mathrm{g} / \mathrm{kg}$ per $0.1 \mathrm{ml}$ infusion volume $)$ or fentanyl-induced reinstatement (15 or $30 \mu \mathrm{g} / \mathrm{kg}$ delivered via subcutaneous [s.c.] injection). The $\alpha 2$ adrenergic antagonist yohimbine $\mathrm{HCl}$ (Sigma-Aldrich, St. Louis, MO) was dissolved in sterile water to prepare the two yohimbine-induced reinstatement doses $(1$ or $2 \mathrm{mg} / \mathrm{kg}$ delivered via intraperitoneal [i.p.] injection). Yohimbine solutions were mixed the day prior to reinstatement and stored at $4^{\circ} \mathrm{C}$ under aluminum foil until needed. All doses were based on salt weight. 


\subsection{Surgical Procedures}

All rats were implanted with chronic indwelling jugular catheters with the port secured to the head using dental acrylic, as described previously (Weiss et al. 2018). For 5 days after surgery, catheters were flushed daily using antibiotic gentamycin solution (0.2 $\mathrm{ml})$, and a post-flush solution ( $0.2 \mathrm{ml}$; consisting of gentamycin, heparin, and saline). Rats received 2-4 additional recovery days, where their catheters were flushed with $0.2 \mathrm{ml}$ postflush solution daily.

\subsection{Operant Conditioning Chambers}

Operant conditioning chambers (MED-Associates, St. Albans, VT) were used and controlled using computers equipped with MED-PC software. Chambers were enclosed in sound-attenuating cabinets with exhaust fans, and were equipped with two levers, two cue lights, a food receptacle, and house light. Levers were located on both sides of one wall and cue lights were mounted above each lever. The food receptacle was positioned between both levers. A house light was located in the upper middle portion of the opposite wall. Syringe pumps outside the sound-attenuating cabinet connected the catheters to a leash inside the operant chamber that moved freely via a swivel connection. During autoshaping and acquisition, fentanyl was delivered in $10 \mathrm{ml}$ syringes at an infusion rate of $0.1 \mathrm{ml}$ per $5.9 \mathrm{sec}$. During the escalation phase, $20 \mathrm{ml}$ syringes were used and fentanyl was delivered at an infusion rate of $0.1 \mathrm{ml}$ per $3.4 \mathrm{sec}$. Syringes were changed as needed during the escalation sessions to avoid syringe emptying. 


\subsection{Autoshaping and Acquisition}

Rats were trained to self-administer fentanyl using an autoshaping procedure for 7 consecutive days. Each day consisted of a 1-h autoshaping session, a 2-h rest in the home cage, and a 1-h operant session. During the autoshaping session, rats were given 5 noncontingent infusions on a 6-min random time schedule across a 35-min period. For each infusion, the active lever would extend for 15-sec and then would retract concomitant with an infusion and illumination of both cue lights for 20-sec; if the rat pressed the lever during the 15 -sec lever extension, the lever was retracted and followed immediately by an infusion and cue light illumination. The active lever was counterbalanced across rats. Following delivery of the 5 infusions, the remaining 25-min of the autoshaping session was spent with both levers retracted. The house light was turned on throughout the autoshaping session. Immediately following each autoshaping session, all rats were placed in their home cage (with ad libitum food and water) for 2-h before returning to the operant chambers for a 1$\mathrm{h}$ operant acquisition session. On this operant session, both the active and inactive levers were continually available, and rats self-administered on a FR1 schedule; the active lever was the same one used during the autoshaping session. Each infusion was paired with 20sec illumination of both cue lights and a time-out period, during which responses were recorded but no infusion was delivered. The house light was turned off throughout the operant acquisition session.

\subsection{Escalation}

After 7 days of acquisition, rats were divided randomly into short access (ShA; $n=16$ males and $n=17$ females) or long access (LgA; $n=16$ males and $n=18$ females) selfadministration groups. For the next 21 daily self-administration sessions, the ShA access 
group was maintained on 1-h sessions, while the LgA group had the session length increased to 6-h. All procedures were the same as described for initial acquisition, except that the autoshaping phase was omitted and session length was changed for LgA rats.

During escalation, some rats began to engage in self-injurious behaviors (digit biting and aggressive grooming). These behaviors were redirected with aspen chew blocks (large, 2 x 1.5 x 1.5 inch: Lomir Biomedical Inc., Malone, NY) placed in the home cage and operant chambers at the start of escalation. Wounds were treated using hibiclens antimicrobial skin liquid soap, $0.9 \%$ bacteriostatic saline, and triple antibiotic ointment after sessions. Areas with persistent wounding were swabbed with a metronidazole and New Skin liquid bandage mixture before, during, and/or after the session as needed.

\subsection{Estrus Cycle Testing}

Immediately prior to each reinstatement session, females received vaginal swabs for estrus cycle testing and males were prodded with swabs to simulate estrus cycle testing. Each female was swabbed twice, once to clean the area of previous dead cells, and the second to collect vaginal wall cells for estrus cycle examination. Following vaginal cell collection, swabs were immediately rolled onto slides and examined under light microscope on the same day.

\subsection{Experiment 1: Fentanyl- and Yohimbine-induced Reinstatement}

Three cohorts of rats (total $n=8$ ShA males, $n=8$ ShA females, $n=8$ LgA males, $\mathrm{n}=8$ LgA females) were used to examine both fentanyl- and yohimbine-induced reinstatement. For both ShA and $\operatorname{LgA}$ groups, rats underwent 14 1-h extinction sessions, which were identical to the acquisition sessions, except that fentanyl infusions were 
omitted. On these sessions, rats were not connected to the metal leash. Reinstatement sessions followed the same format as extinction training, except that rats received one of 5 treatments before the session: (1) $1 \mathrm{mg} / \mathrm{kg}$ yohimbine + vehicle; (2) $2 \mathrm{mg} / \mathrm{kg}$ yohimbine + vehicle; (3) vehicle $+10 \mu \mathrm{g} / \mathrm{kg}$ fentanyl; (4) vehicle $+20 \mu \mathrm{g} / \mathrm{kg}$ fentanyl; or (5) vehicle + vehicle. On each of these reinstatement tests, rats received two injections, with the first injection being yohimbine or water vehicle (i.p.) and the second injection being fentanyl or saline vehicle (s.c.). Injections were separated by $30 \mathrm{~min}$ and rats were placed into the operant conditioning chambers immediately after the second injection. The order of these test treatments was counterbalanced such that all rats received each treatment combination in a counterbalanced order across the 5 reinstatement sessions. Each test session was separated by 5 maintenance extinction sessions (no injections).

\subsection{Experiment 2: Cue-induced Reinstatement and Locomotor Activity}

Two cohorts (total $n=8$ ShA males, $n=9$ ShA females, $n=7$ LgA males, $n=9 \operatorname{LgA}$ females) were used to examine cue-induced reinstatement. For both ShA and LgA groups, rats underwent 14 1-h extinction sessions, which were identical to the acquisition sessions, except that fentanyl infusions, cue light illuminations and leash attachments were omitted. Cue-induced reinstatement was assessed on the day after the final extinction session. During this 1-h reinstatement session, active lever presses resulted in illumination of both cue lights and activation of the syringe pump, but fentanyl was not delivered.

Twenty-four hours after the single cue-induced reinstatement session, each rat was placed into a novel automated activity monitor (Versamax Legacy Open Field activity box, Omnitech Electronics, Columbus, $\mathrm{OH}$ ) and total distance travelled was measured for 1-h. 


\subsection{Statistical Analyses}

Analyses were performed with SAS version 9.4. Multilevel modeling (MLM) procedures were used to assess acquisition, escalation, extinction, and reinstatement. Initial analyses determined whether behavior differed across cohorts. Cohort 5 was the only cohort that differed from other cohorts, thus membership in this cohort was controlled in appropriate models. The general form of the models of acquisition, escalation, and extinction was for lever presses to be modeled as a function of time (session number). Models for extinction data differed in that they took the form of a power model (log of lever pressing predicted by log of time). The general form of the models for reinstatement was for lever presses to be modeled as a function of drug group (vehicle, fentanyl dose, or yohimbine dose) or cue condition, with vehicle or last session of extinction as the reference group, respectively.

A standard model taxonomy was followed (Singer \& Willett 2003), starting with an unconditional means model (UMM), followed by an unconditional growth model (UGM), and subsequent models including variables such as drug condition, access group (ShA or $\operatorname{LgA}$ ), lever type (active or inactive), sex, or interactions between these variables as predictors of initial status and change in lever pressing over time. To determine the preferred model, we examined the improvement in model deviance using the likelihood ratio test ( $\Delta$ deviance). If a variable was unrelated to the dependent variable and its removal did not significantly worsen model fit, it was removed in the final model to maximize parsimony. Additional specifics about models are noted below. Coefficients for the final preferred models are listed in Tables 2.10.1 and 2.10.2. Complete details on each taxonomy are provided in the results. 
Model assumptions were evaluated for preferred models; there were mild to moderate violations of normal residuals and/or homoscedasticity found in each analysis. However, no remedial action successfully alleviated these problems. Therefore, remedial actions were not employed, as ML is robust to mild to moderate violations of assumptions. Data were examined for multivariate outliers, and these observations were replaced as missing in the data analyzed ( $\mathrm{n}=5$ observations across the entire study). All missing data were handled using full information maximum likelihood estimations.

In Experiment 2, linear regression was used to analyze total distance traveled (TDT) during the locomotor activity assessment. 
Table 2.10.1: Preferred model results for acquisition, escalation, and extinction data. The coefficients for the final preferred models for acquisition, escalation, first hour of escalation, Experiment 1 extinction, and Experiment 2 extinction are shown below. Cov $=$ covariance, Var $=$ variance, $-2 \mathrm{LL}=-2 \mathrm{Log}$ Likelihood, $\Delta$ Deviance $=$ delta deviance, $\mathrm{I}=$ intercept, $\mathrm{S}=$ slope, $\mathrm{Q}=$ quadratic. ${ }^{*}(\mathrm{p}<.05),{ }^{* *}(\mathrm{p}<.01),{ }^{* * *}(\mathrm{p}<.001)$, and ${ }^{* * * *}(\mathrm{p}<$ $.0001)$.

\begin{tabular}{|c|c|c|c|c|c|}
\hline \multirow[b]{2}{*}{ Fixed Effects } & \multicolumn{5}{|c|}{ Model } \\
\hline & Acquisition & Escalation & $\begin{array}{c}1^{\text {st }}-\mathbf{h} \\
\text { Escalation } \\
\end{array}$ & $\begin{array}{c}\text { Exp 1. } \\
\text { Extinction }\end{array}$ & $\begin{array}{c}\text { Exp } 2 . \\
\text { Extinction }\end{array}$ \\
\hline \multicolumn{6}{|l|}{ Initial Status } \\
\hline Intercept & $3.96 * * * *$ & 6.90 & $11.99 * * * *$ & $1.55 * * * *$ & $1.82 * * * *$ \\
\hline $\operatorname{LgA}$ & $1.48^{*}$ & $48.38 * * * *$ & -0.72 & $-0.10^{*}$ & $-0.21 * *$ \\
\hline Female & $-1.24 *$ & $12.54 *$ & $2.69 *$ & 0.040 & -0.077 \\
\hline \multicolumn{6}{|l|}{ Session } \\
\hline Intercept & $-0.47 * * *$ & 0.52 & 0.33 & & \\
\hline LgA & -0.29 & $5.56 * * * *$ & $0.78 * *$ & & \\
\hline Female & & -0.28 & 0.11 & & \\
\hline \multicolumn{6}{|l|}{ Session $x$} \\
\hline \multicolumn{6}{|l|}{ Session } \\
\hline Intercept & & -0.0048 & -0.0048 & & \\
\hline $\operatorname{LgA}$ & & -0.084 & -0.0076 & & \\
\hline Female & & -0.0086 & -0.01 & & \\
\hline \multicolumn{6}{|l|}{$\log ($ session $)$} \\
\hline Intercept & & & & $-0.40 * * * *$ & $-0.68 * * * *$ \\
\hline LgA & & & & $0.18 * * *$ & $0.29 * * * *$ \\
\hline Female & & & & 0.059 & -0.040 \\
\hline \multicolumn{6}{|l|}{ Active } \\
\hline Intercept & 0.75 & & & & \\
\hline Female & -0.89 & & & & \\
\hline \multicolumn{6}{|l|}{ Active $x$} \\
\hline \multicolumn{6}{|l|}{ Session } \\
\hline Intercept & $1.51 * * * *$ & & & & \\
\hline Female & $0.73 * *$ & & & & \\
\hline \multicolumn{6}{|l|}{ Random } \\
\hline \multicolumn{6}{|l|}{ Effects } \\
\hline L1 Residual & $13.58 * * * *$ & $188.39 * * * *$ & $13.45 * * * *$ & $0.0092 * * * *$ & $0.025 * * * *$ \\
\hline $\operatorname{Cov}(\mathrm{I}, \mathrm{S})$ & -0.072 & -2.85 & -0.37 & $-0.0098^{*}$ & $-0.020^{*}$ \\
\hline $\operatorname{Var}(\mathrm{I})$ & $1.76^{*}$ & $458.86^{* * * *}$ & $14.22 * * * *$ & $0.018 * * *$ & $0.026 * *$ \\
\hline $\operatorname{Var}(\mathrm{S})$ & 0.011 & $18.61 * * * *$ & $0.86 * * * *$ & $0.012 * *$ & $0.025 * *$ \\
\hline $\operatorname{Cov}(I, Q)$ & & 0.12 & 0.020 & & \\
\hline $\operatorname{Cov}(S, Q)$ & & $-0.74 * * * *$ & $-0.032 * * * *$ & & \\
\hline $\operatorname{Var}(\mathrm{Q})$ & & $0.036^{* * * *}$ & $0.0014 * * * *$ & & \\
\hline$-2 \mathrm{LL}$ & 5404 & 11376.7 & 7733.9 & -706.5 & -295.8 \\
\hline
\end{tabular}


Table 2.10.2: Preferred model results for reinstatement data. The coefficients for the final preferred models for fentanyl-, yohimbine-, and cue-induced reinstatement are shown below. Vehicle is the reference category for the fentanyl and yohimbine models. The last extinction session is the reference category for the cue model. Cov = covariance, Var $=$ variance, $-2 \mathrm{LL}=-2 \log$ Likelihood, $\mathrm{I}=$ intercept. $*(\mathrm{p}<.05), * *(\mathrm{p}<.01), * * *(\mathrm{p}<.001)$, and $* * * *(\mathrm{p}<.0001)$.

\begin{tabular}{|c|c|c|c|}
\hline \multirow[b]{2}{*}{ Fixed Effects } & \multicolumn{3}{|c|}{ Model } \\
\hline & Fentanyl & Yohimbine & Cue \\
\hline \multicolumn{4}{|l|}{ Initial Status } \\
\hline Intercept & $7.39 *$ & $15.09 * * * *$ & $10.80 * * * *$ \\
\hline $\operatorname{LgA}$ & 7.19 & & 2.42 \\
\hline Female & $13.25 * *$ & & -4.18 \\
\hline LgA $x$ Female & -10.06 & & \\
\hline \multicolumn{4}{|l|}{ Fent 10 ug/kg } \\
\hline Intercept & $13.09 * * * *$ & & \\
\hline \multicolumn{4}{|l|}{ Fent $30 \mathrm{ug} / \mathrm{kg}$} \\
\hline Intercept & $9.86^{*}$ & & \\
\hline LgA & $13.06 *$ & & \\
\hline Female & 9.37 & & \\
\hline LgA x Female & -13.69 & & \\
\hline \multicolumn{4}{|l|}{ Yoh 1 mg/kg } \\
\hline Intercept & & $8.34 * * *$ & \\
\hline \multicolumn{4}{|l|}{ Yoh 2 mg/kg } \\
\hline Intercept & & 4.09 & \\
\hline \multicolumn{4}{|l|}{ Cue } \\
\hline Intercept & & & $29.60 * * * *$ \\
\hline $\operatorname{LgA}$ & & & 4.58 \\
\hline Female & & & 2.42 \\
\hline LgA x Female & & & $-20.18 * *$ \\
\hline \multicolumn{4}{|l|}{ Random Effects } \\
\hline L1 Residual & $81.81 * * * *$ & $71.33 * * * *$ & $75.99 * * * *$ \\
\hline $\operatorname{Var}(\mathrm{I})$ & $48.48 * *$ & $59.72 * *$ & 12.59 \\
\hline$-2 \mathrm{LL}$ & 727.9 & 722.3 & 482.6 \\
\hline
\end{tabular}




\section{CHAPTER 3. RESULTS}

\subsection{Experiments 1 and 2: Acquisition}

Data from Experiments 1 and 2 were combined for analysis of the acquisition phase during autoshaped training (Fig. 3.1.1). Active lever pressing increased significantly more over time than inactive lever pressing for both males (difference in change $=1.51, p<.001)$ and females (difference in change $=2.24, p<.001$ ), indicating that all animals acquired fentanyl self-administration. However, acquisition was more pronounced for females, as the difference between active and inactive lever pressing was greater for females than males across sessions (a lever $\mathrm{x}$ session $\mathrm{x}$ sex interaction, $0.73, p<.01$ ). There was no sex difference in change in inactive lever pressing (male change $=-0.48$, female change $=$ $0.77, p>.05$ ), but females increased active lever pressing more rapidly (female change $=$ $1.47, p<.001$ ) than males (male change $=1.03, p<.001$ ); difference in change $=.44, p<$ .01 . On session 1 , females $(M=5.44)$ pressed the inactive lever more than the males $(M=$ 3.96); difference in means $=1.48 p<.05$. There was no difference in active lever pressing between males $(M=4.71)$ and females $(\mathrm{M}=5.30)$ on session $1(p>.05)$. Subjects in Cohort 5 engaged in less lever pressing than other cohorts $(1.24, \mathrm{p}<.05)$. Details of the analysis are provided in Table 3.1.1 and Figure 3.1.2. 


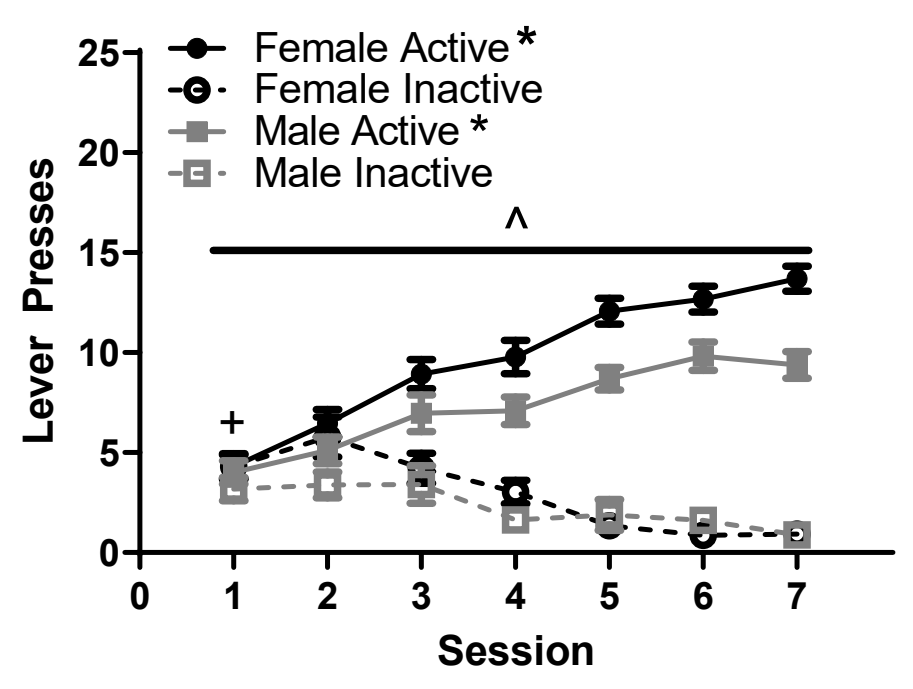

Figure 3.1.1: Acquisition during the autoshaping procedure collapsed across Experiments 1 and 2. Mean $( \pm$ SEM) number of active and inactive lever presses for females and males across 1 -hr sessions. The difference between active and inactive lever change was significant for both males and females *(both $\mathrm{p}<.001)$. The difference between the active and inactive lever change across session was greater in females than males $\wedge^{\wedge}(\mathrm{p}<0.01)$. Females showed higher inactive lever presses on session 1 than males $+(p<.05)$. 
Table 3.1.1: Model results for acquisition collapsed across Experiments 1 and 2. The coefficients from all models performed in the initial acquisition analysis are shown below. Model $\mathrm{C}$ was chosen as the preferred model, considering it provided the last significant increase in delta deviance. Model $\mathrm{C}$ included initial status, session, active, and active $\mathrm{x}$ session as level-1 variables, and included female as a level-2 variable. $\mathrm{Cov}=$ covariance, Var $=$ variance, $-2 \mathrm{LL}=-2 \mathrm{Log}$ Likelihood, $\Delta$ Deviance $=$ delta deviance, $\mathrm{I}=$ intercept, and $\mathrm{S}=$ slope. $*(\mathrm{p}<.05), * *(\mathrm{p}<.01), * * *(\mathrm{p}<.001)$, and $* * * *(\mathrm{p}<.0001)$.

\begin{tabular}{|c|c|c|c|c|c|}
\hline \multirow[b]{2}{*}{ Fixed Effects } & \multicolumn{5}{|c|}{ Model } \\
\hline & UMM & UGM & Model A & Model B & Model C \\
\hline Initial Status & & & & & \\
\hline Intercept & $5.61 * * * *$ & $4.66 * * * *$ & $4.88 * * * *$ & $4.74 * * * *$ & $3.96 * * * *$ \\
\hline $\begin{array}{l}\text { Female } \\
\text { Cohort } 5\end{array}$ & & & & & $1.48 *$ \\
\hline Cohort 5 & & & $-1.27 *$ & $-1.28 *$ & $-1.24 *$ \\
\hline $\begin{array}{l}\text { Session } \\
\text { Intercept }\end{array}$ & & & & & \\
\hline $\begin{array}{l}\text { Intercept } \\
\text { Female }\end{array}$ & & $0.31 * * *$ & $0.32 * * *$ & $-0.63 * * * *$ & $\begin{array}{c}-0.47 * * * \\
-0.29\end{array}$ \\
\hline Active & & & & & \\
\hline Intercept & & & & 0.29 & 0.75 \\
\hline Female & & & & & -0.89 \\
\hline Active $x$ & & & & & \\
\hline Intercept & & & & $1.89 * * * *$ & $1.51 * * * *$ \\
\hline Female & & & & & $0.73 * *$ \\
\hline Random & & & & & \\
\hline L1 Residual & $27.64 * * * *$ & $27.22 * * * *$ & $27.22 * * * *$ & $13.80 * * * *$ & $13.58 * * * *$ \\
\hline $\operatorname{Cov}(\mathrm{I}, \mathrm{S})$ & & -0.11 & -0.058 & -0.024 & -0.072 \\
\hline $\operatorname{Var}(\mathrm{I})$ & $1.28 *$ & 2.00 & 1.42 & $2.19 * *$ & $1.76^{*}$ \\
\hline $\operatorname{Var}(\mathrm{S})$ & & $0 \mathrm{a}$ & $0 \mathrm{a}$ & $0 \mathrm{a}$ & 0.011 \\
\hline $\begin{array}{l}-2 \mathrm{LL} \\
\end{array}$ & 6069.2 & $\begin{array}{c}6054.8 \\
144 * * *\end{array}$ & $\begin{array}{c}6049.7 \\
5.1 *\end{array}$ & $\begin{array}{c}5432.1 \\
6176 * * *\end{array}$ & $\begin{array}{c}5404 \\
281 * * * *\end{array}$ \\
\hline
\end{tabular}




$$
\begin{gathered}
\text { Level 1:y } y=\pi_{0 i}+\pi_{1 i}(\text { Session })+\pi_{2 i}(\text { Active Lever })+ \\
\pi_{3 i}(\text { Active Lever } x \text { Session })+\varepsilon_{i j} \\
\text { Level 2: } \pi_{0 i}=\gamma_{00}+\gamma_{01}(\text { Female })+\gamma_{02}(\text { Cohort } 5)+\zeta_{0 i} \\
\pi_{1 i}=\gamma_{10}+\gamma_{11}(\text { Female })+\zeta_{1 i} \\
\pi_{2 i}=\gamma_{20}+\gamma_{21}(\text { Female }) \\
\pi_{3 i}=\gamma_{30}+\gamma_{31}(\text { Female })
\end{gathered}
$$

Figure 3.1.2: Preferred model for acquisition collapsed across Experiments 1 and 2. The final equation for Model $\mathrm{C}$ for acquisition collapsed across Experiments 1 and 2 is depicted above. 


\subsection{Experiments 1 and 2: Escalation}

Data from Experiments 1 and 2 were combined for analysis of the escalation phase. Two sets of analyses were conducted for escalation. Both sets of analyses followed the general form described in the data analysis section. The first set included data from the full session for each subject (1-h for ShA group and 6-h for $\operatorname{LgA}$ group; Fig. 3.2.1.1). The second set accounted for the different lengths of time between the two access groups by only analyzing the first hour of data from the $\operatorname{LgA}$ group (1-h of data from each access group per session; Fig. 3.2.2.1).

\subsubsection{Results of Model Using Complete Data}

The preferred model included a quadratic term, indicating that the change in active lever pressing followed a curvilinear trajectory for some subjects (LgA rats reach a point where their lever pressing levels off). There was no significant change in active lever pressing across sessions for ShA rats (change $=0.38, p>.05$ ). However, active lever pressing significantly increased across sessions for LgA rats (change $=5.94, p<.001$ ), indicating escalation for $\operatorname{LgA}$ rats. The model also included an interaction between access group and change in active lever pressing across sessions, indicating that the change in active lever pressing across sessions was greater for $\operatorname{LgA}$ rats (difference in change $=5.56$, $p<001)$. Females $(M=43.63)$ pressed the active lever significantly more than males $(M=$ 31.09); difference in means $=12.54, p<.05 . \operatorname{LgA}$ rats $(M=61.55)$ also had greater active lever pressing on session 1 than ShA rats $(M=13.17)$; difference in means $=48.38, p<$ 0.01. Details of the analysis are provided in Table 3.2.1.1 and Figure 3.2.1.2. 


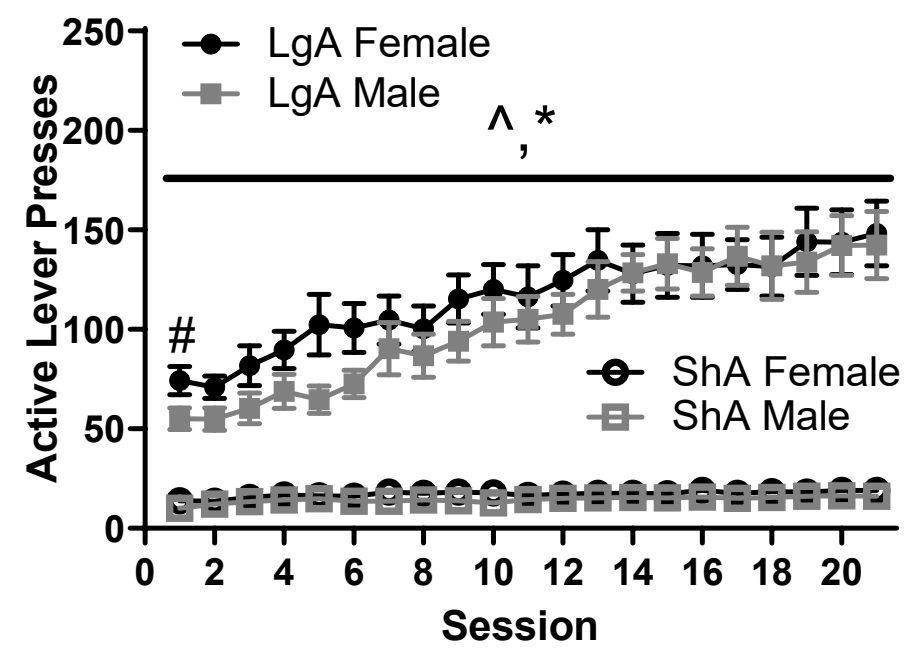

Figure 3.2.1.1: Escalation collapsed across Experiments 1 and 2 using all data. Mean $( \pm$ SEM) number of active lever presses for ShA and LgA females and males across sessions. The LgA group pressed the active lever more on session 1 than the ShA group $\#(\mathrm{p}<.001)$. Females had more active lever presses than males $\wedge(\mathrm{p}<.05)$. LgA rats escalated intake across sessions $*(\mathrm{p}<.001)$, but ShA rats did not $(\mathrm{p}>.05)$. 
Table 3.2.1.1: Model results for escalation collapsed across Experiments 1 and 2 using all data. The coefficients from all models performed in the initial escalation analysis are shown below. Model B was the preferred model, considering it was the final model to show an increase in the delta deviance. Cov $=$ covariance, Var = variance, $-2 \mathrm{LL}=-2 \mathrm{Log}$ Likelihood, $\Delta$ Deviance $=$ delta deviance, $\mathrm{I}=$ intercept, $\mathrm{S}=$ slope, and $\mathrm{Q}=$ quadratic. $*(\mathrm{p}$ $<.05), * *(\mathrm{p}<.01), * * *(\mathrm{p}<.001)$, and $* * * *(\mathrm{p}<.0001)$.

\begin{tabular}{|c|c|c|c|c|c|c|}
\hline \multirow[b]{2}{*}{ Fixed Effects } & \multicolumn{6}{|c|}{ Model } \\
\hline & UMM & UGM & Quadratic & Model A & Model B & Model C \\
\hline \multicolumn{7}{|l|}{ Initial Status } \\
\hline Intercept & $62.41 * * * *$ & $41.39 * * * *$ & $38.02 * * * *$ & $13.35^{* *}$ & 6.90 & $11.945^{*}$ \\
\hline LgA & & & & $48.56 * * * *$ & $48.38 * * * *$ & $38.29 * * * *$ \\
\hline Female & & & & & $12.54 *$ & 2.72 \\
\hline LgA x Female & & & & & & 19.34 \\
\hline \multicolumn{7}{|l|}{ Slope } \\
\hline Intercept & & $2.13 * * * *$ & $3.18 * * * *$ & 0.37 & 0.52 & 0.35 \\
\hline $\operatorname{LgA}$ & & & & $\begin{array}{c}5.5574 * * * \\
*\end{array}$ & $\begin{array}{c}5.5634 * * * \\
*\end{array}$ & $5.90 * * *$ \\
\hline Female & & & & & -0.2771 & 0.050 \\
\hline LgA x Female & & & & & & -0.65 \\
\hline \multicolumn{7}{|l|}{ Quadratic } \\
\hline Intercept & & & $-0.053 *$ & -0.0092 & -0.0048 & -0.0071 \\
\hline $\operatorname{LgA}$ & & & & -0.084 & -0.084 & -0.079 \\
\hline Female & & & & & -0.0086 & -0.0042 \\
\hline LgA $x$ Female & & & & & & -0.0094 \\
\hline \multicolumn{7}{|l|}{ Random } \\
\hline \multicolumn{7}{|l|}{ Effects } \\
\hline L1 Residual & $678.16 * * * *$ & $231.85 * * * *$ & $188.41 * * * *$ & $\begin{array}{c}188.37 * * * \\
*\end{array}$ & $\begin{array}{c}188.39 * * * \\
*\end{array}$ & $188.41 * * *$ \\
\hline $\operatorname{Cov}(\mathrm{I}, \mathrm{S})$ & & $53.58 * * * *$ & $64.11 * *$ & -3.75 & -2.85 & -2.058 \\
\hline Var (I) & $\begin{array}{c}3089.68 * * * \\
*\end{array}$ & $\begin{array}{c}1327.03 * * * \\
*\end{array}$ & $\begin{array}{c}1086.52 * * * \\
*\end{array}$ & $\begin{array}{c}498.33 * * * \\
*\end{array}$ & $\begin{array}{c}458.86^{* * *} \\
*\end{array}$ & $\begin{array}{c}435.05 * * * \\
*\end{array}$ \\
\hline $\operatorname{Var}(\mathrm{S})$ & & $7.23 * * * *$ & $26.24 * * * *$ & $18.66^{* * * *}$ & $18.61 * * * *$ & $18.57 * * * *$ \\
\hline $\operatorname{Cov}(I, Q)$ & & & -0.94 & 0.097 & 0.12 & 0.12 \\
\hline $\operatorname{Cov}(S, Q)$ & & & $0.8501 * * * *$ & $-0.74 * * * *$ & $-0.74 * * * *$ & $-0.74 * * * *$ \\
\hline $\operatorname{Var}(\mathrm{Q})$ & & & $\begin{array}{c}0.03704^{* * * *} \\
*\end{array}$ & $0.036^{* * * *}$ & $0.036^{* * * * *}$ & $0.036 * * * *$ \\
\hline$-2 \mathrm{LL}$ & 12850.4 & 11618.3 & 11463.2 & 11382.4 & 11376.7 & 11372.9 \\
\hline$\Delta$ Deviance & & $1232.1 * * * *$ & $155.1 * * * *$ & $80.8 * * * *$ & $5.7 *$ & 3.8 \\
\hline
\end{tabular}




$$
\begin{aligned}
& \text { Level 1: } y=\pi_{0 i}+\pi_{1 i}(\text { Session })+\pi_{2 i}(\text { Session } x \text { Session })+\varepsilon_{i j} \\
& \text { Level 2: } \pi_{0 i}=\gamma_{00}+\gamma_{01}(\operatorname{LgA})+\gamma_{02}(\text { Female })+\zeta_{0 i} \\
& \pi_{1 i}=\gamma_{10}+\gamma_{11}(\operatorname{Lg} A)+\gamma_{12}(\text { Female })+\zeta_{1 i} \\
& \pi_{2 i}=\gamma_{20}+\gamma_{21}(\operatorname{Lg} A)+\gamma_{22}(\text { Female })+\zeta_{2 i}
\end{aligned}
$$

Figure 3.2.1.2: Preferred model for escalation collapsed across Experiments 1 and 2 using all data. The final equation for Model B for escalation collapsed across Experiments 1 and 2 using all data is depicted above. 


\subsubsection{Results of Model Using Only First Hour of Data Per Session}

Results are similar to those of the prior set of analyses. The preferred model included a quadratic term, indicating that change in active lever pressing followed a curvilinear trajectory for some rats (female $\operatorname{LgA}$ rats reach a point where their lever pressing levels off). There was no significant change in active lever pressing across sessions for ShA rats (change $=0.39, p>.05$ ). However, active lever pressing significantly increased over time for $\mathrm{LgA}$ rats (change $=1.17, p<.001$ ), indicating escalation for $\operatorname{LgA}$ rats. The model also included an interaction between access group and change in active lever pressing across sessions, suggesting that the change in active lever pressing across sessions was greater for $\operatorname{LgA}$ rats (difference in change $=0.78, p<.01)$. Females $(M=$ 14.32) pressed the active lever significantly more than males $(M=11.63)$; difference in means $=2.69, p<.05$. Details of the analysis are provided in Table 3.2.2.1 and Figure

\subsubsection{2.}




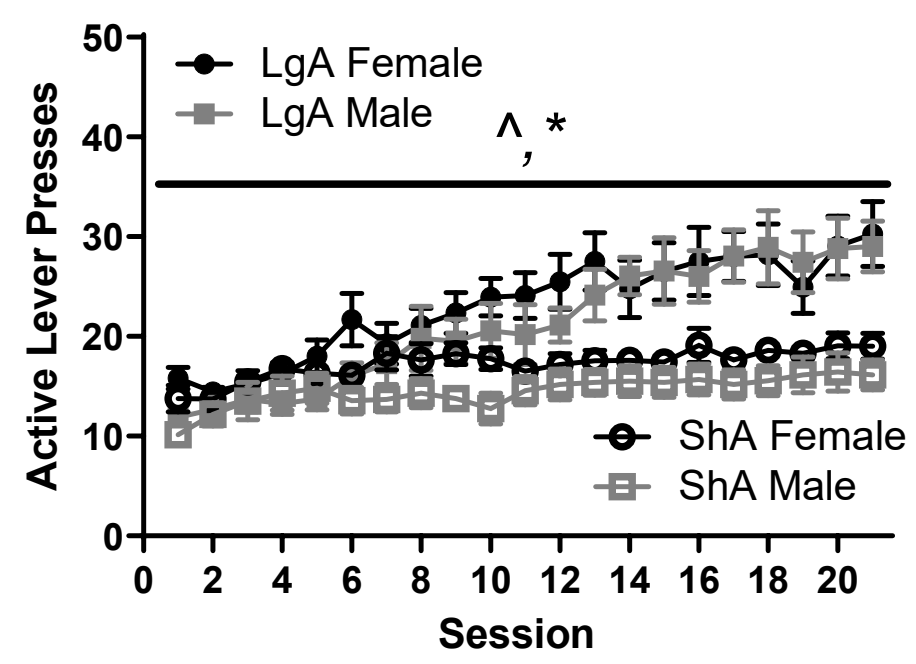

Figure 3.2.2.1: Escalation collapsed across Experiments 1 and 2 using the first hour of each session. Mean $( \pm \mathrm{SEM})$ number of active lever presses for ShA and $\mathrm{LgA}$ females and males across sessions. Females had more active lever presses than males $\wedge^{\wedge}(p<.05)$. LgA rats escalated intake across session $*(\mathrm{p}<.001)$, but ShA rats did not $(\mathrm{p}>.05)$. 
Table 3.2.2.1: Model results for escalation collapsed across Experiments 1 and 2 using the first hour of each session. The coefficients from all models performed in the initial first hour of escalation analysis are shown below. The taxonomy for the first hour of escalation is analogous to the escalation taxonomy. $\mathrm{Cov}=$ covariance, $\mathrm{Var}=$ variance, $-2 \mathrm{LL}=-2 \mathrm{Log}$ Likelihood, $\Delta$ Deviance $=$ delta deviance, $\mathrm{I}=$ intercept, $\mathrm{S}=$ slope, and $\mathrm{Q}=$ quadratic. $*(\mathrm{p}$ $<.05), * *(\mathrm{p}<.01), * * *(\mathrm{p}<.001)$, and $* * * *(\mathrm{p}<.0001)$.

\begin{tabular}{|c|c|c|c|c|c|c|}
\hline \multirow[b]{2}{*}{ Fixed Effects } & \multicolumn{6}{|c|}{ Model } \\
\hline & UMM & UGM & Quadratic & Model A & Model B & Model C \\
\hline \multicolumn{7}{|l|}{ Initial Status } \\
\hline Intercept & $\begin{array}{c}18.90^{*} \\
* * *\end{array}$ & $\begin{array}{c}13.92 * \\
* * *\end{array}$ & $13.028 * * * *$ & $13.38^{* * * *}$ & $11.99 * * * *$ & $11.96^{* * * *}$ \\
\hline $\operatorname{LgA}$ & & & & -0.69 & -0.72 & -0.67 \\
\hline Female & & & & & $2.69 *$ & 2.75 \\
\hline LgA x Female & & & & & & -0.12 \\
\hline \multicolumn{7}{|l|}{ Slope } \\
\hline Intercept & & $\begin{array}{c}0.51 * * \\
* *\end{array}$ & $0.78 * * * *$ & $0.38^{*}$ & 0.33 & 0.35 \\
\hline $\operatorname{LgA}$ & & & & $0.79 * *$ & $0.78^{* *}$ & $0.75^{*}$ \\
\hline Female & & & & & 0.11 & 0.074 \\
\hline LgA x Female & & & & & & 0.066 \\
\hline \multicolumn{7}{|l|}{ Quadratic } \\
\hline Intercept & & & $-0.014 *$ & -0.0099 & -0.0048 & -0.0070 \\
\hline LgA & & & & -0.0079 & -0.0076 & -0.0029 \\
\hline Female & & & & & -0.010 & -0.0056 \\
\hline LgA x Female & & & & & & -0.0090 \\
\hline \multicolumn{7}{|l|}{ Random Effects } \\
\hline L1 Residual & $\begin{array}{c}34.50^{*} \\
* * *\end{array}$ & $\begin{array}{c}15.30 * \\
* * *\end{array}$ & $13.44 * * * *$ & $13.44 * * * *$ & $13.45^{* * * *}$ & $13.44 * * * *$ \\
\hline $\operatorname{Cov}(\mathrm{I}, \mathrm{S})$ & & 0.15 & -0.37 & -0.30 & -0.37 & -0.37 \\
\hline $\operatorname{Var}(\mathrm{I})$ & $\begin{array}{c}47.95^{*} \\
* * *\end{array}$ & $\begin{array}{c}19.79 * \\
* * *\end{array}$ & $15.93 * * * *$ & $16.02 * * * *$ & $14.22 * * * *$ & $14.21 * * * *$ \\
\hline $\operatorname{Var}(\mathrm{S})$ & & $\begin{array}{c}0.26^{* *} \\
* *\end{array}$ & $1.00 * * * *$ & $0.86^{* * * *}$ & $0.86^{* * * *}$ & $0.86^{* * * *}$ \\
\hline $\operatorname{Cov}(I, Q)$ & & & 0.012 & 0.014 & 0.020 & 0.020 \\
\hline $\operatorname{Cov}(S, Q)$ & & & $-0.033 * * * *$ & $-0.032 * * * *$ & $-0.032 * * * *$ & $-0.032 * * * *$ \\
\hline $\operatorname{Var}(\mathrm{Q})$ & & & $0.0014 * * * *$ & $0.0015 * * * *$ & $0.0014 * * * *$ & $0.0014 * * * *$ \\
\hline$-2 \mathrm{LL}$ & 8785 & 7866.2 & 7774 & 7743.6 & 7733.9 & 7733.3 \\
\hline$\Delta$ Deviance & & $\begin{array}{c}918.8^{*} \\
* * *\end{array}$ & $92.2 * * * *$ & $30.4 * * * *$ & $9.7 *$ & 0.6 \\
\hline
\end{tabular}




$$
\begin{aligned}
& \text { Level 1: } y=\pi_{0 i}+\pi_{1 i}(\text { Session })+\pi_{2 i}(\text { Session } x \text { Session })+\varepsilon_{i j} \\
& \text { Level 2: } \pi_{0 i}=\gamma_{00}+\gamma_{01}(\operatorname{LgA})+\gamma_{02}(\text { Female })+\zeta_{0 i} \\
& \pi_{1 i}=\gamma_{10}+\gamma_{11}(\operatorname{Lg} A)+\gamma_{12}(\text { Female })+\zeta_{1 i} \\
& \pi_{2 i}=\gamma_{20}+\gamma_{21}(\operatorname{Lg} A)+\gamma_{22}(\text { Female })+\zeta_{2 i}
\end{aligned}
$$

Figure 3.2.2.2: Preferred model for escalation collapsed across Experiments 1 and 2 using the first hour of each session. The final equation for Model B for escalation collapsed across Experiments 1 and 2 using the first hour of each session is depicted above. 


\subsection{Experiments 1 and 2: Extinction}

Since extinction conditions differed between Experiments 1 and 2, separate analyses were conducted for each experiment. For Experiment 1 (Fig. 3.3.1), there was an effect of access group on session 1 active lever pressing and change in active lever pressing across sessions. LgA rats $(M=1.46)$ engaged in less $\log ($ active lever presses) than ShA rats $(M=1.57)$ during session 1 ; difference in means $=-0.10, p \leq .05$. LgA rats exhibited less decay in responding (change $=-0.19, p<.001)$ than ShA rats (change $=-0.37, p<$ .001 ) difference in change $=.18, p<.001$. Details of the analysis are provided in Table

\subsection{1 and Figure 3.3.2.}

For Experiment 2 (Fig. 3.3.3), results were similar. There was an effect of access group on session 1 active lever pressing and change in active lever pressing across sessions. LgA rats $(M=1.57)$ engaged in less $\log ($ active lever presses $)$ than ShA rats $(M=1.78, p<$ .0001 ) during session 1; difference in means $=-.21, p=<.01$. LgA rats also exhibited less decay in responding $($ change $=-0.41, p<.001)$ than ShA rats $($ change $=-0.70, p<.001)$; difference in change $=0.29, p<.0001$. Details of the analysis are provided in Table 3.3.2 and Figure 3.3.4. 


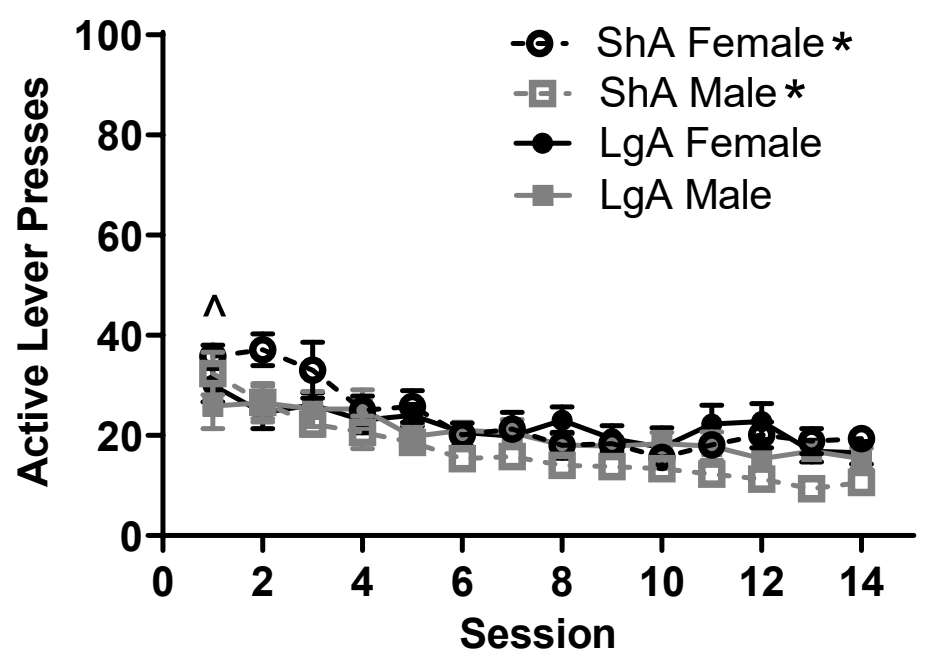

Figure 3.3.1: Extinction in Experiment 1 with cue light maintained. Mean ( \pm SEM) number of active lever presses for ShA and LgA females and males across sessions. LgA rats pressed the active lever less than ShA rats on session $1^{\wedge}(p<.05)$. The LgA group showed less decay of active lever pressing than the ShA group $*(p<.001)$. 
Table 3.3.1: Model results for extinction in Experiment 1 with cue light maintained. The coefficients from all models performed in the initial Experiment 1 extinction analysis are shown below. Model B was the preferred model. Cov $=$ covariance, Var $=$ variance, $-2 \mathrm{LL}$ $=-2$ Log Likelihood, $\Delta$ Deviance $=$ delta deviance, $\mathrm{I}=$ intercept, and $\mathrm{S}=$ slope. $*(\mathrm{p}<.05)$, $* *(\mathrm{p}<.01), * * *(\mathrm{p}<.001)$, and $* * * *(\mathrm{p}<.0001)$.

\begin{tabular}{|c|c|c|c|c|c|}
\hline \multirow[b]{2}{*}{ Fixed Effects } & \multicolumn{5}{|c|}{ Model } \\
\hline & UCM & UCG & Model A & Model B & Model C \\
\hline \multicolumn{6}{|l|}{ Initial Status } \\
\hline Intercept & $1.30 * * * *$ & $1.52 * * * *$ & $1.57 * * * *$ & $1.55 * * * *$ & $1.54 * * * *$ \\
\hline $\operatorname{LgA}$ & & & -0.10 & $-0.10^{*}$ & -0.086 \\
\hline Female & & & & 0.040 & 0.058 \\
\hline LgA x Female & & & & & -0.035 \\
\hline \multicolumn{6}{|l|}{$\log ($ Session) } \\
\hline Intercept & & $-0.28 * * * *$ & $-0.37 * * * *$ & $-0.40 * * * *$ & $-0.42 * * * *$ \\
\hline LgA & & & $0.18 * * *$ & $0.18 * * *$ & $0.23 * * *$ \\
\hline Female & & & & 0.059 & 0.11 \\
\hline LgA x Female & & & & & -0.095 \\
\hline \multicolumn{6}{|l|}{ Random } \\
\hline Effects & & & & & \\
\hline L1 Residual & $0.020 * * * *$ & $0.0092 * * * *$ & $0.0092 * * * *$ & $0.0092 * * * *$ & $0.0092 * * * *$ \\
\hline $\operatorname{Cov}(\mathrm{I}, \mathrm{S})$ & & $-0.014 *$ & $-0.0092 *$ & $-0.0098^{*}$ & $-0.010^{*}$ \\
\hline Var (I) & $0.011 * * *$ & $0.021 * * *$ & $0.018 * * *$ & $0.018 * * *$ & $0.018 * * *$ \\
\hline $\operatorname{Var}(\mathrm{S})$ & & $0.021 * *$ & $0.013 * *$ & $0.012 * *$ & $0.011 * *$ \\
\hline$-2 \mathrm{LL}$ & -403.5 & -688.5 & -700 & -706.5 & -710.1 \\
\hline$\Delta$ Deviance & & $* * * * 285$ & $* * 11.5$ & $* 6.5$ & 3.6 \\
\hline
\end{tabular}




$$
\begin{gathered}
\text { Level 1: } \log (y)=\pi_{0 i}+\pi_{1 i}(\log (\operatorname{Session}))+\varepsilon_{i j} \\
\text { Level 2: } \pi_{0 i}=\gamma_{00}+\gamma_{01}(\operatorname{LgA})+\gamma_{02}(\text { Female })+\zeta_{0 i} \\
\pi_{1 i}=\gamma_{10}+\gamma_{11}(\operatorname{Lg} A)+\gamma_{12}(\text { Female })+\zeta_{1 i}
\end{gathered}
$$

Figure 3.3.2: Preferred model for extinction in Experiment 1 with cue light maintained. The final equation for Model B for extinction in Experiment 1 with cue light maintained is depicted above. 


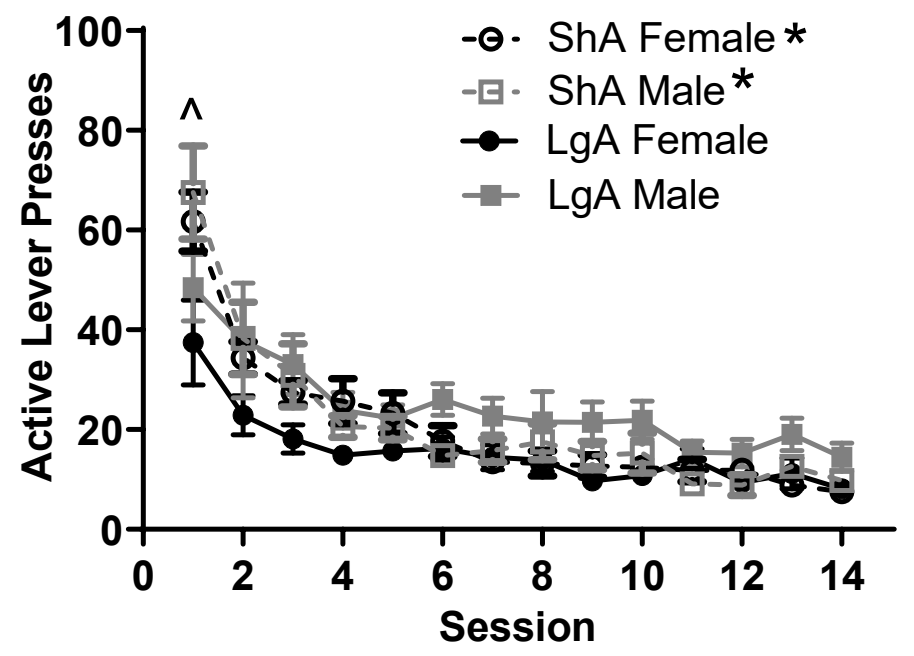

Figure 3.3.3: Extinction in Experiment 2 with cue light omitted. Mean $( \pm \mathrm{SEM})$ number of active lever presses for ShA and LgA females and males across sessions. ShA animals pressed the active lever more than $\operatorname{LgA}$ animals ${ }^{\wedge}(\mathrm{p}<.05)$. The $\operatorname{LgA}$ group showed less decay of active lever pressing than the ShA group * $(\mathrm{p}<.001)$. 
Table 3.3.2: Model results for extinction in Experiment 2 with cue light omitted. The coefficients from all models performed in the initial Experiment 2 extinction analysis are shown below. Model B was the preferred model, considering it was the last to have a significant increase in delta deviance score. $\mathrm{Cov}=$ covariance, $\operatorname{Var}=$ variance, $-2 \mathrm{LL}=-2$ Log Likelihood, $\Delta$ Deviance $=$ delta deviance, $\mathrm{I}=$ intercept, and $\mathrm{S}=$ slope. $*(\mathrm{p}<.05),{ }^{* *}(\mathrm{p}$ $<.01), * * *(\mathrm{p}<.001)$, and $* * * *(\mathrm{p}<.0001)$.

\begin{tabular}{lccccc}
\hline & \multicolumn{5}{c}{ Model } \\
\cline { 2 - 6 } Fixed Effects & UCM & UCG & Model A & Model B & Model C \\
\hline Initial status & & & & & \\
Intercept & $1.23^{* * * *}$ & $1.67 * * * *$ & $1.78^{* * * *}$ & $1.82^{* * * *}$ & $1.77 * * *$ \\
LgA & & & $-0.22^{* *}$ & $-0.21^{* *}$ & -0.12 \\
Female & & & & -0.077 & 0.0098 \\
LgA x Female & & & & & -0.18 \\
Log(Session) & & & & & \\
Intercept & & $-0.57 * * * *$ & $-0.71 * * * *$ & $-0.68^{* * * *}$ & $-0.68^{* * * *}$ \\
LgA & & & $0.29^{* * * *}$ & $0.29 * * * *$ & $0.29^{* *}$ \\
Female & & & & -0.040 & -0.040 \\
LgA x Female & & & & & 0.0011 \\
Random & & & & & \\
Effects & & & & & \\
\hline L1 Residual & $0.067 * * * *$ & $0.025^{* * * *}$ & $0.025^{* * * *}$ & $0.025^{* * * *}$ & $0.025^{* * * *}$ \\
Cov (I,S) & & $-0.035^{* *}$ & $-0.019 *$ & $-0.020^{*}$ & $-0.020^{*}$ \\
Var (I) & $0.011^{* *}$ & $0.040^{* * *}$ & $0.028^{* *}$ & $0.026^{* *}$ & $0.024 * *$ \\
Var (S) & & $0.046^{* *}$ & $0.025^{* *}$ & $0.025^{* *}$ & $0.025^{* *}$ \\
\hline-2 LL & 97.8 & -275.6 & -288.7 & -295.8 & -301.4 \\
$\Delta$ Deviance & & $* * * * 373.4$ & $* * * 13.1$ & $* 7.1$ & 5.6 \\
\hline
\end{tabular}




$$
\begin{gathered}
\text { Level 1: } \log (y)=\pi_{0 i}+\pi_{1 i}(\log (\operatorname{Session}))+\varepsilon_{i j} \\
\text { Level 2: } \pi_{0 i}=\gamma_{00}+\gamma_{01}(\operatorname{LgA})+\gamma_{02}(\text { Female })+\zeta_{0 i} \\
\pi_{1 i}=\gamma_{10}+\gamma_{11}(\operatorname{Lg} A)+\gamma_{12}(\text { Female })+\zeta_{1 i}
\end{gathered}
$$

Figure 3.3.4: Preferred model for extinction in Experiment 2 with cue light omitted. The final equation for Model B for extinction in Experiment 2 with cue light omitted is depicted above. 


\subsection{Experiment 1: Fentanyl-induced Reinstatement}

As shown in Fig. 3.4.1, results indicated that active lever pressing was greater after $10 \mu \mathrm{g} / \mathrm{kg}$ fentanyl $(M=28.19)$ compared to vehicle $(M=15.10) ;$ mean difference $=13.09$, $p<.001$, indicating reinstatement for all rats at this dose. There was also an interaction between access group and the effect of $30 \mu \mathrm{g} / \mathrm{kg}$ fentanyl $(13.06, p<.05)$. ShA rats exhibited greater active lever pressing after $30 \mu \mathrm{g} / \mathrm{kg}$ fentanyl than after vehicle (difference $=14.55, p<.05)$, indicating reinstatement. However, the difference between $30 \mu \mathrm{g} / \mathrm{kg}$ fentanyl and vehicle active lever responding was even larger in $\operatorname{LgA}$ rats (difference $=$ $20.77, p<.001)$, indicating greater reinstatement for the LgA group. Regardless of access group, females exhibited greater active lever pressing than males (difference in means $=$ 8.22, $p<0.05$ ); there was no significant difference in females based on metestrus/diestrus $v s$ proestrus $v s$ estrus phases (results not shown).

The analysis of data in Fig. 3.4.1 indicated a near significant interaction between access group, sex, and the effect of $30 \mu \mathrm{g} / \mathrm{kg}$ fentanyl, $-13.68, p=.085$. Given the small sample size, this 3-way interaction was probed. The difference between $30 \mu \mathrm{g} / \mathrm{kg}$ fentanyl and vehicle was significantly greater for $\operatorname{LgA}$ males (difference in means $=22.92, p<.001$ ) than ShA males (difference in means $=9.86, p<.05)$, with the difference in differences $=$ 13.06, $p<.05$. In contrast, the difference between $30 \mu \mathrm{g} / \mathrm{kg}$ fentanyl and vehicle was the same for LgA females (difference in means $=18.61, p<.001)$ and ShA females (difference in means $=19.23, p<.001$ ), with the difference in differences $=0.63, p>.05$; there was no significant difference in females based on metestrus/diestrus $v s$ proestrus $v s$ estrus phases (results not shown). Thus, based on this exploratory analysis, the effect of $30 \mu \mathrm{g} / \mathrm{kg}$ fentanyl was moderated by access group only for males. Details of the analysis are provided in Table 3.4.1 and Figure 3.4.2. 


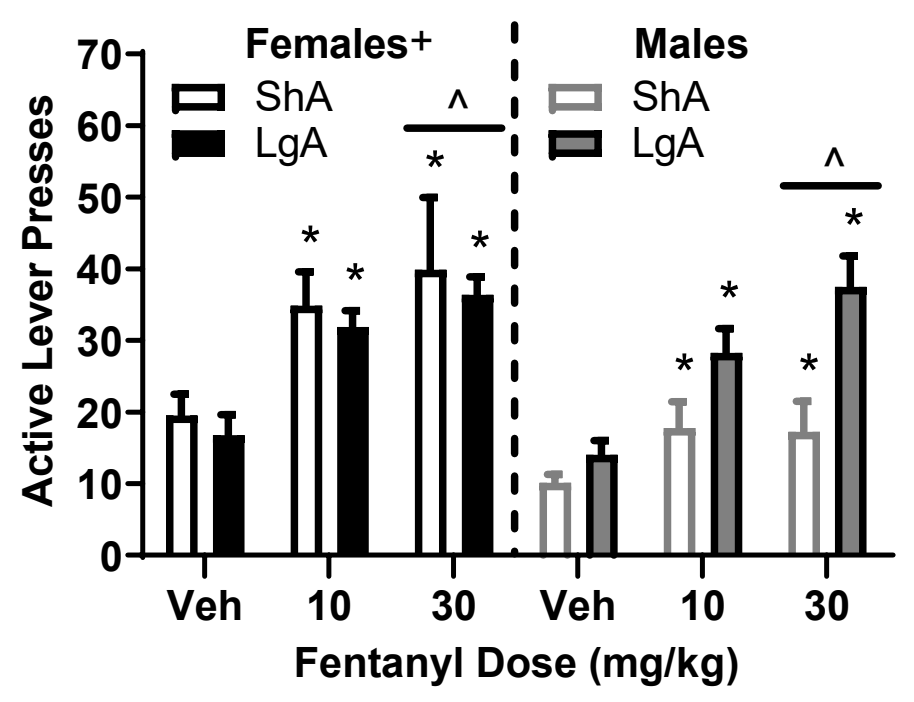

Figure 3.4.1: Fentanyl-induced reinstatement in Experiment 1. Mean ( \pm SEM) number of active lever presses for ShA and $\mathrm{LgA}$ females and males following vehicle, $10 \mathrm{ug} / \mathrm{kg}$ fentanyl, and $30 \mathrm{ug} / \mathrm{kg}$ fentanyl. All rats reinstated to $10 \mathrm{ug} / \mathrm{kg}$ and $30 \mathrm{ug} / \mathrm{kg}$ fentanyl in comparison to vehicle $*(\mathrm{p}<.05)$. The difference between vehicle and $30 \mathrm{ug} / \mathrm{kg}$ fentanyl responding was greater for the $\operatorname{LgA}$ group $\wedge^{\wedge}(\mathrm{p}<.05)$. Females had higher active lever responding than males overall $+(\mathrm{p}<.01)$. LgA males reinstated more than ShA males at the $30 \mathrm{ug} / \mathrm{kg}$ fentanyl dose $(\mathrm{p}<.05)$. 
Table 3.4.1: Model results for fentanyl-induced reinstatement in Experiment 1. The coefficients from all models performed in the initial fentanyl-induced reinstatement analysis are shown below. Model E was chosen as the preferred model, considering it was the most parsimonious model and did not increase in delta deviance from the previous model with a significant delta deviance. This model did not include any level- 2 predictors for $10 \mathrm{ug} / \mathrm{kg}$ fentanyl, since previously all level-2 predictors were non-significant. Vehicle responding served as the reference category. Fent $=$ fentanyl, Cov $=$ covariance, Var $=$ variance, $-2 \mathrm{LL}=-2 \mathrm{Log}$ Likelihood, $\Delta$ Deviance $=$ delta deviance, and I $=$ intercept. * $(\mathrm{p}$ $<.05), * *(\mathrm{p}<.01), * * *(\mathrm{p}<.001)$, and $* * * *(\mathrm{p}<.0001)$.

\begin{tabular}{|c|c|c|c|c|c|c|}
\hline \multirow[b]{2}{*}{ Fixed Effects } & \multicolumn{6}{|c|}{ Model } \\
\hline & UCM & Model A & Model B & Model C & Model D & Model E \\
\hline \multicolumn{7}{|l|}{ Initial Status } \\
\hline Intercept & $25.34 * * * *$ & $15.09 * * * *$ & $14.81 * * * *$ & $11.78 * *$ & $10.13^{*}$ & $7.39 *$ \\
\hline $\operatorname{LgA}$ & & & 0.56 & 0.56 & 3.88 & 7.19 \\
\hline Female & & & & 6.06 & 9.38 & $13.25 * *$ \\
\hline LgA $x$ Female & & & & & -6.63 & -10.06 \\
\hline \multicolumn{7}{|l|}{ Fent 10 ug/kg } \\
\hline Intercept & & $13.09 * * * *$ & $11.50 * * *$ & $9.34 *$ & 7.63 & $13.094 * * * *$ \\
\hline LgA & & & 3.19 & 3.19 & 6.63 & \\
\hline Female & & & & 0.35 & 7.75 & \\
\hline LgA x Female & & & & & -6.88 & \\
\hline \multicolumn{7}{|l|}{ Fent 30 ug/kg } \\
\hline Intercept & & $17.66 * * * *$ & $13.75 * * * *$ & $11.41 * *$ & 7.13 & $9.86^{*}$ \\
\hline $\operatorname{LgA}$ & & & 7.81 & 7.81 & $16.38^{*}$ & $13.06^{*}$ \\
\hline Female & & & & 4.69 & $13.25^{*}$ & 9.37 \\
\hline LgA $x$ Female & & & & & -17.13 & -13.69 \\
\hline \multicolumn{7}{|l|}{ Random } \\
\hline \multicolumn{7}{|l|}{ Effects } \\
\hline L1 Residual & $173.47 * * * *$ & $89.47 * * * *$ & $85.61 * * * *$ & $83.91 * * * *$ & $79.27 * * * *$ & $81.81 * * * *$ \\
\hline $\operatorname{Var}(\mathrm{I})$ & $56.30 *$ & $84.30 * *$ & $81.11^{* *}$ & $61.15 * *$ & $49.33 * *$ & $48.48 * *$ \\
\hline$-2 \mathrm{LL}$ & 789.2 & 746.8 & 742.7 & 734.8 & 725.9 & 727.9 \\
\hline$\Delta$ Deviance & & $* * * * 42.4$ & 4.1 & $* 7.9$ & $* 8.9$ & 2 \\
\hline
\end{tabular}




$$
\begin{aligned}
& \text { Level 1: } y=\pi_{0 i}+\pi_{1 i}(10 \mathrm{ug} / \mathrm{kg} \text { Fentanyl })+\pi_{2 i}(30 \mathrm{ug} / \mathrm{kg} \mathrm{Fentanyl})+\varepsilon_{i j} \\
& \text { Level 2: } \pi_{0 i}=\gamma_{00}+\gamma_{01}(\operatorname{Lg} A)+\gamma_{02}(\text { Female })+\gamma_{03}(\operatorname{LgAx} \text { Female })+\zeta_{0 i} \\
& \pi_{1 i}=\gamma_{10} \\
& \pi_{2 i}=\gamma_{20}+\gamma_{21}(\text { LgA })+\gamma_{22}(\text { Female })+\gamma_{23}(\text { LgA x Female })
\end{aligned}
$$

Figure 3.4.2: Preferred model for fentanyl-induced reinstatement in Experiment 1. The final equation for Model E for fentanyl-induced reinstatement in Experiment 1 is depicted above. 


\subsection{Experiment 1: Yohimbine-induced Reinstatement}

The preferred model included only the dummy variables for 1 and $2 \mathrm{mg} / \mathrm{kg}$ yohimbine as predictors of active lever pressing. Sex, access group, and interactions between sex and access group did not improve model fit and were not significant predictors of active lever pressing. As shown in Fig. 3.5.1, active lever pressing was greater after 1 $\mathrm{mg} / \mathrm{kg}$ yohimbine $(M=23.43, p<.001)$ compared to vehicle $(M=15.09, p<.0001)$; difference in means $=8.34, p<.001$, indicating that rats reinstated at this yohimbine dose. Active lever pressing was marginally greater following $2 \mathrm{mg} / \mathrm{kg}$ yohimbine group $(M=$ $19.18, p<.001)$ compared to vehicle $(M=15.09, p<.0001)$; difference in means $=4.09$, $p=.06$. Details of the analysis are provided in Table 3.5.1 and Figure 3.5.2. 


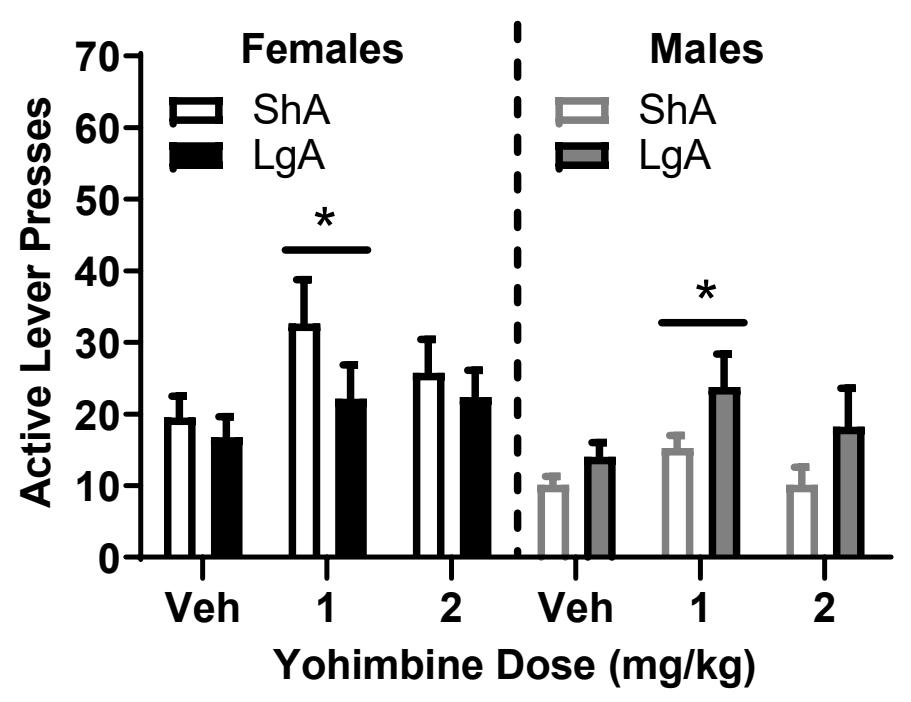

Figure 3.5.1: Yohimbine-induced reinstatement in Experiment 1. Mean ( \pm SEM) number of active lever presses for ShA and $\operatorname{LgA}$ females and males following vehicle, $1 \mathrm{mg} / \mathrm{kg}$ yohimbine, and $2 \mathrm{mg} / \mathrm{kg}$ yohimbine. The $1 \mathrm{mg} / \mathrm{kg}$ yohimbine dose produced reinstatement in comparison to vehicle, collapsed across access group and sex $*(p<.001)$. 
Table 3.5.1: Model results for yohimbine-induced reinstatement in Experiment 1. The coefficients from all models performed in the initial yohimbine-induced reinstatement analysis are shown below. Model A was the preferred model, because adding each level-2 predictor in the following models did not significantly increase the delta deviance. Vehicle responding served as the reference category. Yoh $=$ yohimbine, $\mathrm{Cov}=$ covariance, $\mathrm{Var}=$ variance, $-2 \mathrm{LL}=-2 \mathrm{Log}$ Likelihood, $\Delta$ Deviance $=$ delta deviance, and I $=$ intercept. $*(p$ $<.05), * *(p<.01), * * *(p<.001)$, and $* * * *(p<.0001)$.

\begin{tabular}{|c|c|c|c|c|c|}
\hline \multirow[b]{2}{*}{ Fixed Effects } & \multicolumn{5}{|c|}{ Model } \\
\hline & UCM & Model A & Model B & Model C & Model D \\
\hline \multicolumn{6}{|l|}{ Initial Status } \\
\hline Intercept & $19.24 * * * *$ & $15.09 * * * *$ & $14.81 * * * *$ & $11.78 * *$ & $10.125 * *$ \\
\hline $\operatorname{LgA}$ & & & 0.56 & 0.56 & 3.88 \\
\hline Female & & & & 6.06 & 9.37 \\
\hline LgA $x$ female & & & & & -6.63 \\
\hline \multicolumn{6}{|l|}{ Yoh $1 \mathrm{mg} / \mathrm{kg}$} \\
\hline Intercept & & $8.34 * * *$ & $9.13 * *$ & $8.22 *$ & 5.13 \\
\hline LgA & & & -1.56 & -1.56 & 4.63 \\
\hline Female & & & & 0.66 & 8 \\
\hline LgA x Female & & & & & -12.38 \\
\hline \multicolumn{6}{|l|}{ Yoh $2 \mathrm{mg} / \mathrm{kg}$} \\
\hline Intercept & & 4.09 & 3.25 & 1.41 & 0.25 \\
\hline LgA & & & 1.69 & 1.69 & 4 \\
\hline Female & & & & 3.69 & 6 \\
\hline LgA $x$ Female & & & & & -4.63 \\
\hline \multicolumn{6}{|l|}{ Random } \\
\hline \multicolumn{6}{|l|}{ Effects } \\
\hline L1 Residual & $88.74 * * * *$ & $71.33 * * * *$ & $70.67 * * * *$ & $69.82 * * * *$ & $67.38 * * * *$ \\
\hline $\operatorname{Var}(\mathrm{I})$ & $53.92 * *$ & $59.72 * *$ & $59.85 * *$ & $44.55 * *$ & $32.92 * *$ \\
\hline$-2 \mathrm{LL}$ & 736.3 & 722.3 & 721.7 & 714.3 & 707.2 \\
\hline$\Delta$ Deviance & & $* * * * 14.0$ & 0.6 & 7.4 & 7.1 \\
\hline
\end{tabular}




$$
\begin{gathered}
\text { Level 1: } y=\pi_{0 i}+\pi_{1 i}(1 \mathrm{mg} / \mathrm{kg} \text { Yohimbine })+\pi_{2 i}(2 \mathrm{mg} / \mathrm{kg} \text { Yohimbine })+\varepsilon_{i j} \\
\text { Level } 2: \pi_{0 i}=\gamma_{00}+\zeta_{0 i} \\
\pi_{1 i}=\gamma_{10} \\
\pi_{2 i}=\gamma_{20}
\end{gathered}
$$

Figure 3.5.2: Preferred model for yohimbine-induced reinstatement in Experiment 1. The final equation for Model A for yohimbine-induced reinstatement in Experiment 1 is depicted above 


\subsection{Experiment 2: Cue-induced Reinstatement}

As shown in Fig. 3.6.1, there was a 3-way interaction between cue condition, sex, and access group, $-20.18, p<.01$. All groups exhibited cue-induced reinstatement. Cueinduced reinstatement in $\operatorname{LgA}$ females (difference between cue and extinction $=16.42, p<$ .0001) was significantly less than in ShA females (difference between cue and extinction $=32.02, p<.0001)$; difference in reinstatement $=15.60, p<.01$. However, cue-induced reinstatement in $\operatorname{LgA}$ males (difference between cue and extinction $=34.17, p<.0001$ ) was not significantly different from ShA males (difference between cue and extinction $=$ 29.60, $p<.0001$ ); difference in reinstatement $=4.58, p>.05$. Thus, the effect of access group on cue-induced reinstatement was only observed for females; there was no significant difference in females based on metestrus/diestrus $v s$ proestrus $v s$ estrus phases (results not shown).

Additional probing of the 3-way interaction examined how sex differences varied across the access groups. Cue-induced reinstatement for LgA males (difference between cue and extinction $=34.17, p<.0001$ ) was significantly greater than LgA females (difference between cue and extinction $=16.42, p<.0001)$; difference in reinstatement $=$ $17.75, p<.01$. However, cue-induced reinstatement for ShA males (difference between cue and extinction $=29.60, p<.0001)$ was not significantly different from ShA females (difference between cue and extinction $=32.02, p<.0001)$; difference in reinstatement $=$ $2.43, p>.05$. Thus, a sex difference was only observed for LgA rats. Details of the analysis are provided in Table 3.6.1 and Figure 3.6.2. 


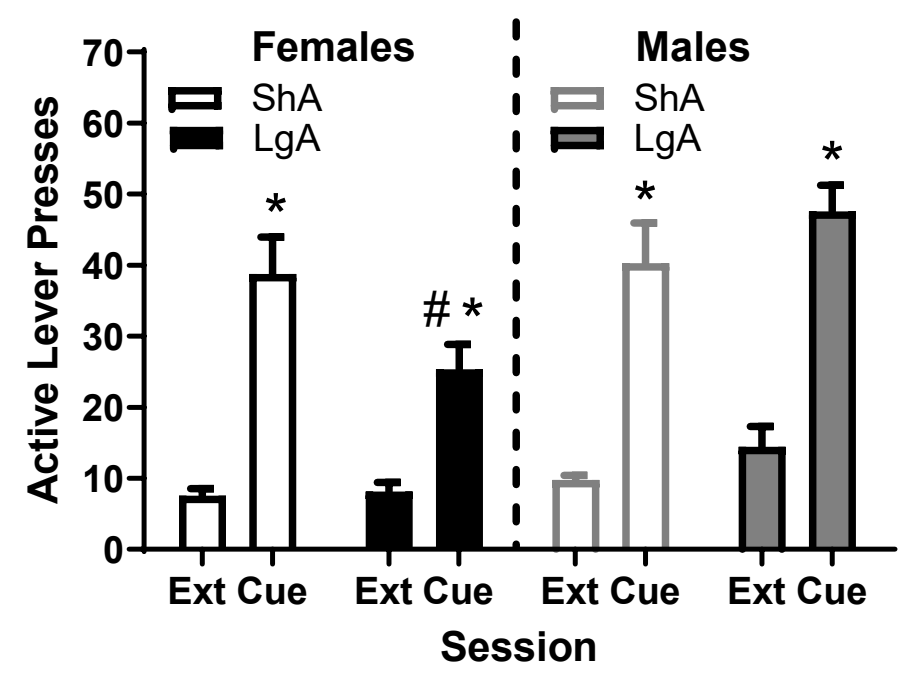

Figure 3.6.1: Cue-induced reinstatement in Experiment 2. Mean $( \pm S E M)$ number of active lever presses for ShA and LgA females and males following the final extinction session (Ext) or cue-induced reinstatement (Cue). All rats reinstated to the cue in comparison to their final extinction session $*(p<.001)$. There was also a significant cue $\mathrm{x}$ access group $\mathrm{x}$ sex interaction, indicating the difference between the final extinction session between access groups was moderated by sex, with $\operatorname{LgA}$ females showing less reinstatement than LgA males \# $(\mathrm{p}<.01)$. 
Table 3.6.1: Model results for cue-induced reinstatement in Experiment 2. The coefficients from all models performed in the initial cue-induced reinstatement analysis are shown below. Model D was chosen as the final preferred model because it maximized parsimony and did not have a delta deviance higher than the previous model with a significant delta deviance. Last extinction session responding served as the reference category. Cov $=$ covariance, $\operatorname{Var}=$ variance, $-2 \mathrm{LL}=-2 \mathrm{Log}$ Likelihood, $\Delta$ Deviance $=$ delta deviance, and $\mathrm{I}=$ intercept. $*(\mathrm{p}<.05), * *(\mathrm{p}<.01), * * *(\mathrm{p}<.001)$, and $* * * *(\mathrm{p}<.0001)$.

\begin{tabular}{lccccc}
\hline & & \multicolumn{3}{c}{ Model } \\
\cline { 2 - 6 } Fixed Effects & UMM & Model A & Model B & Model C & Model D \\
\hline Initial Status & & & & & \\
Intercept & $23.52 * * * *$ & $9.70^{* * * *}$ & $8.59 * *$ & $9.75^{* *}$ & $10.80^{* * * *}$ \\
LgA & & & 2.29 & 4.68 & 2.43 \\
Female & & & & -2.19 & -4.18 \\
LgA x Female & & & -4.12 & \\
Cue & & & & \\
Intercept & & $27.64 * * * *$ & $30.88^{* * * *}$ & $30.50^{* * * *}$ & $29.60^{* * * *}$ \\
LgA & & -6.69 & 2.64 & 4.58 \\
Female & & & & 0.72 & 2.43 \\
LgA x Female & & & & -16.64 & $-20.18 * *$ \\
Random & & & & & \\
Effects & & & & \\
\hline L1 Residual & $314.40^{* * * *}$ & $96.36^{* * * *}$ & $90.76^{* * * *}$ & $75.61 * * * *$ & $75.99 * * * *$ \\
Var (I) & $0 \mathrm{a}$ & 27.10 & 29.61 & 12.44 & 12.59 \\
\hline -2 LL & 566.8 & 503.5 & 501.4 & 482.2 & 482.6 \\
$\Delta$ Deviance & & $* * * * 63.3$ & 2.1 & $* * 19.2$ & 0.4 \\
\hline
\end{tabular}




$$
\begin{gathered}
\text { Level 1:y }=\pi_{0 i}+\pi_{1 i}(\mathrm{Cue})+\varepsilon_{i j} \\
\text { Level 2: } \pi_{0 i}=\gamma_{00}+\gamma_{01}(\text { LgA })+\gamma_{02}(\text { Female })+\zeta_{0 i} \\
\pi_{1 i}=\gamma_{10}+\gamma_{11}(\text { LgA })+\gamma_{12}(\text { Female })+\gamma_{13}(\text { LgA } x \text { Female })
\end{gathered}
$$

Figure 3.6.2: Preferred model for cue-induced reinstatement in Experiment 2. The final equation for Model D for cue-induced reinstatement in Experiment 2 is depicted above. 


\subsection{Experiment 2: Locomotor Activity Following Cue-induced Reinstatement}

To assess whether the reduced reinstatement responding of $\operatorname{LgA}$ females merely reflected a general decrease in behavior, the locomotor results on the day following the last reinstatement test in Experiment 2 are summarized in Fig. 3.7.1. Because only one observation per rat was available, multiple linear regression of locomotor activity was used to test hypotheses. Models were similar in form to the cue-induced reinstatement model described above (sex, access group, and the sex $\mathrm{x}$ access group interaction were included as independent variables). Results indicated a significant sex $\mathrm{x}$ access group interaction, $B$ $=3773.32, p<.001$. For males, locomotor activity was greater for LgA rats $(M=6894.78)$ than ShA rats $(M=5471.40), B=1423.38, p<.05$. For females, locomotor activity was less for $\operatorname{LgA}$ rats $(M=8601.89)$ than ShA rats $(M=10952.00), B=2349.94, p<.001$. Thus, LgA sessions increased locomotor activity for males and decreased locomotor activity for females. For ShA rats, locomotor activity was greater in females $(M=$ 10952.00) than males $(M=5471.40), B=5480.43, p<.001$. A similar, but smaller effect was found between LgA females $(M=8601.89)$ and males $(M=6894.78), B=1707.11, p$ $<.01$. Thus, females showed greater overall locomotor activity in comparison to males. 


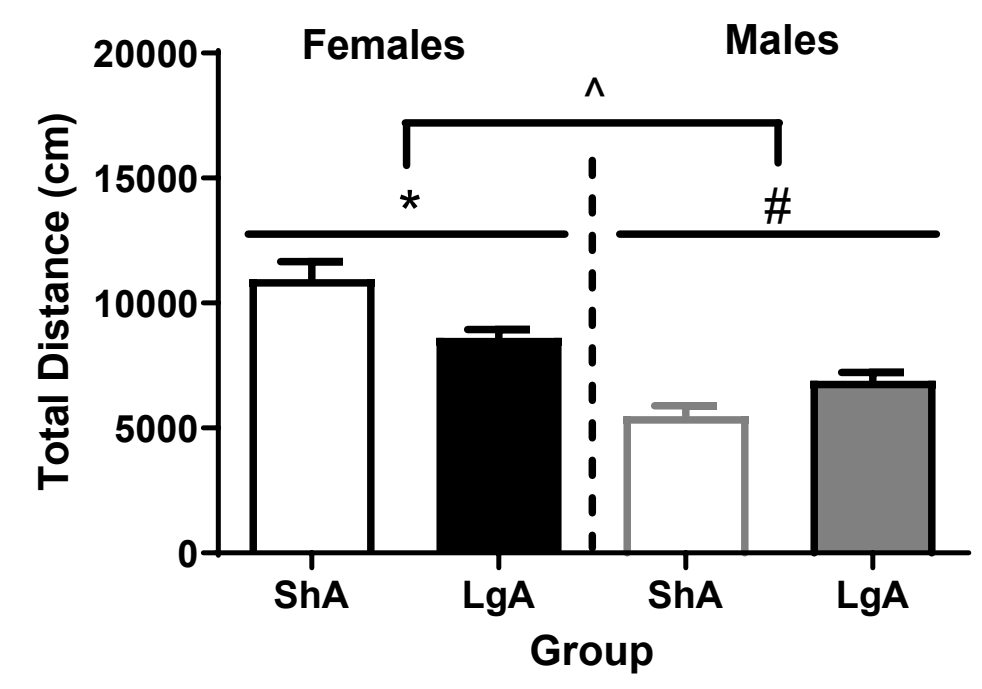

Figure 3.7.1: Locomotor activity 24-h following cue-induced reinstatement test in Experiment 2. Mean $( \pm$ SEM) distance traveled ShA and LgA females and males. There was a significant sex $x$ access group interaction ${ }^{\wedge}(p<.001)$. LgA females expressed less activity than ShA females $*(\mathrm{p}<.001)$; however, $\operatorname{LgA}$ males expressed more activity than ShA males \# $(\mathrm{p}<.05)$. 


\section{CHAPTER 4. DISCUSSION}

With the goal of determining if escalation of fentanyl intake and reinstatement of fentanyl seeking are related in males and females, the current study revealed several key findings. First, during acquisition using an autoshaping procedure in ShA (1-h) sessions, females acquired self-administration at a faster rate than males. Second, when switched to LgA (6-h) sessions, both sexes escalated intake across the 21 sessions. No escalation was obtained with either sex when rats were maintained on ShA sessions. Females selfadministered more than males, regardless of access length. Third, during the extinction phase, $\operatorname{LgA}$ rats responded less than ShA rats on the first session and they experienced a slower decay of responding. Fourth, and most importantly, ShA and LgA groups showed a differential pattern of response to the stimuli used during reinstatement testing (fentanyl, yohimbine, cue). With drug-primed reinstatement, the difference in responding between vehicle and $30 \mu \mathrm{g} / \mathrm{kg}$ fentanyl responding was greater in LgA males than ShA males. With yohimbine, only the lower dose of yohimbine $(1 \mathrm{mg} / \mathrm{kg})$ produced reinstatement and no difference between ShA and LgA groups was observed. With cue-primed reinstatement, there was a 3-way interaction (cue condition $\mathrm{x}$ access group $\mathrm{x}$ sex) effect which indicated that cue-induced reinstatement in LgA females was reduced compared to both LgA males and ShA females. Thus, while LgA sessions were related to greater drug-primed reinstatement, particularly in males, $\operatorname{LgA}$ sessions were not related to greater reinstatement induced by either yohimbine or a drug-associated cue.

Evidence indicates that females may be more susceptible than males to the reinforcing effect of drugs of abuse in both clinical and preclinical settings (Lynch et al., 2002). In rats, previous studies indicate that females have increased vulnerability to the 
acquisition of cocaine and heroin self-administration, and successfully acquire selfadministration in fewer days than males (Lynch \& Carroll, 1999; Carroll et al., 2001; Carroll et al., 2002). A similar effect is found in other substances of abuse such as nicotine, methamphetamine, and alcohol (Lynch et al., 2002). Evidence suggests that accelerated acquisition of drug self-administration in females may be a result of estradiol activity (Hu et al., 2004; Jackson et al., 2006; Lynch, 2006). Similar to results obtained with cocaine and heroin, the current results demonstrate that females acquire the self-administration of fentanyl at a faster rate than males. However, females may also have greater lever-press sampling behavior early in acquisition to facilitate acquisition, as they also showed greater responding on the inactive lever than males on the first session.

Although prior research indicates that rats given extended access (6- to12-h) to drug-reinforced responding will escalate their intake across sessions, much of this work has been conducted with stimulant drugs. For example, cocaine self-administration in rats escalates when maintained on 6- and 12-h sessions, but not when maintained on 1- or 3-h sessions (Wee et al., 2007). LgA females also show a more robust escalation in cocaine self-administration compared to LgA males (Roth \& Carroll, 2004). More recent work has demonstrated that escalation of intake also occurs with opioid self-administration. Rats placed on LgA self-administration sessions escalate heroin self-administration across 18 sessions, but not when placed on ShA self-administration sessions (Ahmed et al., 2000). Furthermore, when rats are placed on LgA fentanyl self-administration sessions, they escalate their intake across sessions (Wade et al., 2015; Morgan et al., 2002). However, since those previous studies with fentanyl were with males only, our results extend those findings to demonstrate both males and females escalate their intake of fentanyl similarly 
when given $\operatorname{LgA}$ but not ShA sessions. Moreover, the current results indicate that females express greater active lever pressing for fentanyl than males during self-administration, regardless of session length.

It is well known that rats extinguish drug seeking when the emitted behavior does not lead to drug delivery (McNally, 2014). A few studies have shown that extinction of self-administration behavior may vary depending on the length of the self-administration session. For example, one study found that $\operatorname{LgA}$ rats extinguished slower than ShA rats (Lenoir \& Ahmed, 2007). Consistent with that report, the current study found that when extinction was performed with or without previous drug-associated cues, LgA rats showed a less rapid decay of non-reinforced responding compared ShA rats. Paradoxically, however, ShA rats showed higher responding than LgA rats on the first extinction session. This latter result contradicts a previous report that ShA rats show less active lever pressing than LgA rats early in extinction of lever pressing established with heroin (Ahmed et al., 2000). While a number of procedural differences exist between studies that prevents a firm explanation of the discrepant findings, the current results indicate that the transient "extinction burst" that occurs on the first session of reward omission is greatest in ShA rats, perhaps because they temporally learn during acquisition to emit all of their responses within one hour.

Drug-primed reinstatement is a common method of inducing drug seeking following a period of extinction. Rats that previously self-administered cocaine, nicotine, alcohol, or heroin all show reinstatement after extinction when the self-administered drug is reintroduced (De Vries et al., 1998; Feltenstein et al., 2012; Le et al., 1998; Shaham et al., 1994). While it is known that drug seeking can be achieved following a drug prime, 
little research has examined how extended access can alter this type of reinstatement. Mantsch et al. (2004) found that rats previously maintained on LgA (7-h) sessions were more sensitive to cocaine-induced reinstatement than rats previously maintained on ShA (1-h) sessions. Similarly, more robust heroin-induced reinstatement was found in rats trained on LgA (6-h) sessions than rats trained on ShA (1-h) sessions (Lenoir \& Ahmed, 2006). Consistent with those previous reports, which were in only males, the current results demonstrate that $\operatorname{LgA}$ rats show greater fentanyl-induced reinstatement after fentanyl (30 $\mu \mathrm{g} / \mathrm{kg}$ ) compared to ShA rats. However, this effect was driven primarily by the difference in reinstatement between $\mathrm{LgA}$ and $\mathrm{ShA}$ males, suggesting that the relation between escalation and drug-primed reinstatement may be specific to males.

Yohimbine has been used in previous research to trigger drug seeking following a period of extinction (Mantsch et al., 2014; See \& Waters, 2011). Yohimbine-induced reinstatement occurs in rats following self-administration of methamphetamine (Shepard et al., 2004), cocaine (Feltenstein \& See, 2006), alcohol (Lee et al., 2004), and nicotine (Feltenstein et al., 2012), although fentanyl seeking has not been examined. The current results indicate that reliable reinstatement occurred with $1 \mathrm{mg} / \mathrm{kg}$ yohimbine, but not 2 $\mathrm{mg} / \mathrm{kg}$ yohimbine. However, this low-dose reinstatement effect did not differ between access group or sex, which contrasts with drug-primed reinstatement. Importantly, recent evidence indicates that yohimbine appears to produce anxiety- and stress-like symptoms that may produce response enhancement that is independent of past drug use (Mantsch et al., 2016; Chen et al., 2015), thus calling into question its validity as a marker of stressinduced reinstatement. 
In another group of rats (Experiment 2), cue-induced reinstatement was also assessed. Reintroducing a cue previously associated with drug taking is another wellknown method of producing drug seeking following self-administration of alcohol (Schroeder et al., 2008), cocaine (Sutton et al., 2000), nicotine (Le Foll et al., 2012), heroin (Rubio et al., 2019) and methamphetamine (Yan et al., 2007). However, little is known about cue-induced reinstatement after the escalation of drug taking. One study found no difference between ShA and $\operatorname{LgA}$ adult or adolescent male rats in cue-induced morphine seeking (Doherty, 2009). Similarly, the current study found no difference between ShA and LgA males. Interestingly, however, LgA females showed reduced cue-induced reinstatement compared to either ShA females or LgA males. This may reflect, at least in part, a generalized decrease in activity, as $\operatorname{LgA}$ females also displayed less locomotion than ShA females when tested in a different context; conversely, LgA males displayed more locomotion than ShA males. The decrease in both cue-induced reinstatement and locomotor activity observed in LgA females may involve changes in corticotropinreleasing factor (CRF) systems, as CRF in the reward-relevant ventral tegmental area is associated with cocaine-associated cue learning (Tovar-Diaz et al., 2018) and sex differences exist in activation of CRF neurocircuitry (Salvatore et al., 2018). Further work is needed to determine if escalation of fentanyl intake in females leads to lasting changes in CRF or other reward-relevant systems underlying cue-induced fentanyl seeking.

In conclusion, the current study provides only limited support for the hypothesis that escalation of fentanyl intake and reinstatement of drug seeking are related processes since LgA sessions produced greater reinstatement than ShA session to a drug prime, but not to either yohimbine or a cue, and the drug prime effect was limited to males. In 
addition, LgA males displayed greater cue-induced reinstatement than LgA females. These results are consistent with clinical data indicating that males are more reactive to cocaineassociated cues than females (Frick, 2020). In addition, while some human research indicates that females are more susceptible to craving and relapse (Becker, 2016; Robbins et al., 1999; Fox et al., 2014; Hitschfeld et al., 2015), other studies support that males have worse outcomes following treatment, despite predicted advantages (Walitzer \& Dearing, 2006). Sex differences also occur in relapse patterns, with males oscillating more quickly between relapse and abstinence compared to females (Gallop et al., 2007). Further work is needed to uncover the potential mechanisms involved in the sex-dependent differences in reinstatement observed here following $\operatorname{LgA}$ sessions. 


\section{REFERENCES}

Ahmed, S., Walker, J., \& Koob, G. (2000). Persistent increase in the motivation to take heroin in rats with a history of drug escalation. Neuropsychopharmacology 22: 413421. Neuropsychopharmacology, 22, 413-421. https://doi.org/10.1016/S0893$133 X(99) 00133-5$

Akorn, Inc. (2017). Fentanyl citrate injection. Lake forest, IL: Akorn, Inc.

Allain, F., Bouayad-Gervais, K., \& Samaha, A. N. (2018). High and escalating levels of cocaine intake are dissociable from subsequent incentive motivation for the drug in rats. Psychopharmacology (Berl), 235(1), 317-328.

https://doi.org/10.1007/s00213-017-4773-8

American Psychiatric Association. (2013). Diagnostic and statistical manual of mental disorders: DSM-5 (Fifth edition. ed.). Arlington, VA: American Psychiatric Association.

Banks, W. A. (2009). Characteristics of compounds that cross the blood-brain barrier. BMC Neurology, 9(1), S3. https://doi.org/10.1186/1471-2377-9-S1-S3

Beardsley, P. M., \& Shelton, K. L. (2012). Prime-, stress-, and cue-induced reinstatement of extinguished drug-reinforced responding in rats: cocaine as the prototypical drug of abuse. Current protocols in neuroscience, Chapter 9, Unit9.39-39.39. https://doi.org/10.1002/0471142301.ns0939s61

Becker, J. B. (2016). Sex differences in addiction. Dialogues in clinical neuroscience, $18(4), 395-402$.

Becker, J. B., \& Koob, G. F. (2016). Sex Differences in Animal Models: Focus on Addiction. Pharmacol Rev, 68(2), 242-263. https://doi.org/10.1124/pr.115.011163 
Becker, J. B., McClellan, M. L., \& Reed, B. G. (2017). Sex differences, gender and addiction. Journal of neuroscience research, 95(1-2), 136-147. https://doi.org/10.1002/jnr.23963

Blakemore, P., \& White, J. (2002). Morphine, the Proteus of organic molecules. Chemical communications (Cambridge, $\quad$ England), $\quad$ 1159-1168. https://doi.org/10.1039/B111551K

Bodnar, R. J. (2013). Endogenous opiates and behavior: 2012. Peptides, 50, 55-95. https://doi.org/https://doi.org/10.1016/j.peptides.2013.10.001

Boom, M., Niesters, M., Sarton, E., Aarts, L., Smith, T. W., \& Dahan, A. (2012). Nonanalgesic effects of opioids: opioid-induced respiratory depression. Curr Pharm Des, 18(37), 5994-6004. https://doi.org/10.2174/138161212803582469

Boscarino, J. A., Hoffman, S. N., Gerhard, G., Han, J., Rukstalis, M., Erlich, P. M., \& Stewart, W. F. (2010). PS2-13: Genetic and Environmental Risk Factors for Prescription Opioid Dependence in the Healthcare Setting. Clinical Medicine \& Research, 8(1), 51-51. https://doi.org/10.3121/cmr.8.1.51

Bremner, J. D., Krystal, J. H., Southwick, S. M., \& Charney, D. S. (1996a). Noradrenergic mechanisms in stress and anxiety: I. preclinical studies. Synapse, 23(1), 28-38. https://doi.org/10.1002/(sici)1098-2396(199605)23:1<28::Aid-syn4>3.0.Co;2-j

Bremner, J. D., Krystal, J. H., Southwick, S. M., \& Charney, D. S. (1996b). Noradrenergic mechanisms in stress and anxiety: II. Clinical studies. Synapse, 23(1), 39-51. https://doi.org/10.1002/(sici)1098-2396(199605)23:1<39::Aid-syn5>3.0.Co;2-i 
Brownstein, M. J. (1993). A brief history of opiates, opioid peptides, and opioid receptors. Proceedings of the National Academy of Sciences of the United States of America, 90(12), 5391-5393. https://doi.org/10.1073/pnas.90.12.5391

Bull, F. A., Baptista-Hon, D. T., Lambert, J. J., Walwyn, W., \& Hales, T. G. (2017). Morphine activation of mu opioid receptors causes disinhibition of neurons in the ventral tegmental area mediated by $\beta$-arrestin2 and c-Src. Scientific Reports, 7(1), 9969. https://doi.org/10.1038/s41598-017-10360-8

Burcher, K. M., Suprun, A., \& Smith, A. (2018). Risk Factors for Opioid Use Disorders in Adult Postsurgical Patients. Cureus, 10(5), e2611-e2611. https://doi.org/10.7759/cureus.2611

Butour, J.-L., Moisand, C., Mazarguil, H., Mollereau, C., \& Meunier, J.-C. (1997). Recognition and activation of the opioid receptor-like ORL1 receptor by nociceptin, nociceptin analogs and opioids. European Journal of Pharmacology, 32l(1), 97-103. https://doi.org/https://doi.org/10.1016/S0014-2999(96)00919-3

Carroll, J. J., Marshall, B. D. L., Rich, J. D., \& Green, T. C. (2017). Exposure to fentanylcontaminated heroin and overdose risk among illicit opioid users in Rhode Island: A mixed methods study. International Journal of Drug Policy, 46, 136-145. https://doi.org/10.1016/j.drugpo.2017.05.023

Carroll, M. E., Campbell, U. C., \& Heideman, P. (2001). Ketoconazole Suppresses Food Restriction-Induced Increases in Heroin Self-Administration in Rats: Sex Differences. Experimental and Clinical Psychopharmacology, 9(3), 307-316. https://doi.org/10.1037/1064-1297.9.3.307 
Carroll, M. E., Morgan, A. D., Lynch, W. J., Campbell, U. C., \& Dess, N. K. (2002). Intravenous cocaine and heroin self-administration in rats selectively bred for differential saccharin intake: phenotype and sex differences. Psychopharmacology (Berl), 161(3), 304-313. https://doi.org/10.1007/s00213-002-1030-5

Center for Disease Control. (2011). Vital Signs: Overdoses of Prescription Opioid Pain Relievers --- United States, 1999--2008. Retrieved July 07, 2020, from https://www.cdc.gov/mmwr/preview/mmwrhtml/mm6043a4.htm

Center for Disease Control. (2019). Synthetic Opioid Overdose Data. Retrieved from https://www.cdc.gov/drugoverdose/data/fentanyl.html

Center for Disease Control. (2020). Fentanyl. Retrieved July 06, 2020, from https://www.cdc.gov/drugoverdose/opioids/fentanyl.html

Center for Disease Control. (2020). Understanding the Epidemic. Retrieved July 07, 2020, from https://www.cdc.gov/drugoverdose/epidemic/index.html

Chalana, H., Kundal, T., Gupta, V., \& Malhari, A. S. (2016). Predictors of Relapse after Inpatient Opioid Detoxification during 1-Year Follow-Up. Journal of Addiction, 2016. https://doi.org/10.1155/2016/7620860

Chen, Y. W., Fiscella, K. A., Bacharach, S. Z., Tanda, G., Shaham, Y., \& Calu, D. J. (2015). Effect of yohimbine on reinstatement of operant responding in rats is dependent on cue contingency but not food reward history. Addiction Biology, 20(4), 690-700. https://doi.org/10.1111/adb.12164

Cicero, T. J., Aylward, S. C., \& Meyer, E. R. (2003). Gender differences in the intravenous self-administration of mu opiate agonists. Pharmacol Biochem Behav, 74(3), 541549. https://doi.org/10.1016/s0091-3057(02)01039-0 
Cifani, C., Koya, E., Navarre, B. M., Calu, D. J., Baumann, M. H., Marchant, N. J., Liu, Q. R., Khuc, T., Pickel, J., Lupica, C. R., Shaham, Y., \& Hope, B. T. (2012). Medial prefrontal cortex neuronal activation and synaptic alterations after stress-induced reinstatement of palatable food seeking: a study using c-fos-GFP transgenic female rats. $J$ Neurosci, 32(25), 8480-8490. https://doi.org/10.1523/jneurosci.589511.2012

Cocker, P. J., Rotge, J.-Y., Daniel, M.-L., Belin-Rauscent, A., \& Belin, D. (2020). Impaired decision making following escalation of cocaine self-administration predicts vulnerability to relapse in rats. Addiction Biology, 25(3), e12738-e12738. https://doi.org/10.1111/adb.12738

Comer, S. D., Sullivan, M. A., Vosburg, S. K., Manubay, J., Amass, L., Cooper, Z. D., Saccone, P., \& Kleber, H. D. (2010). Abuse liability of intravenous buprenorphine/naloxone and buprenorphine alone in buprenorphine-maintained intravenous heroin abusers. Addiction (Abingdon, England), 105(4), 709-718. https://doi.org/10.1111/j.1360-0443.2009.02843.x

Corbett, A. D., Henderson, G., McKnight, A. T., \& Paterson, S. J. (2006). 75 years of opioid research: the exciting but vain quest for the Holy Grail. British journal of pharmacology, $\quad 147 \quad$ Suppl 1 (Suppl $\quad 1), \quad$ S153-S162. https://doi.org/10.1038/sj.bjp.0706435

Dahan, A., van der Schrier, R., Smith, T., Aarts, L., van Velzen, M., \& Niesters, M. (2018). Averting Opioid-induced Respiratory Depression without Affecting Analgesia. Anesthesiology, 128(5), 1027-1037. https://doi.org/10.1097/aln.0000000000002184 
De Vries, T. J., Schoffelmeer, A. N., Binnekade, R., Mulder, A. H., \& Vanderschuren, L. J. (1998). Drug-induced reinstatement of heroin- and cocaine-seeking behaviour following long-term extinction is associated with expression of behavioural sensitization. Eur J Neurosci, 10(11), 3565-3571. https://doi.org/10.1046/j.14609568.1998.00368.x

DePriest, A. Z., Puet, B. L., Holt, A. C., Roberts, A., \& Cone, E. J. (2015). Metabolism and Disposition of Prescription Opioids: A Review. Forensic science review, 27(2), 115-145. http://europepmc.org/abstract/MED/26227254

Doherty, J., Ogbomnwan, Y., Williams, B., \& Frantz, K. (2009). Age-dependent morphine intake and cue-induced reinstatement, but not escalation in intake, by adolescent and adult male rats. Pharmacology, biochemistry, and behavior, 92(1), 164-172. https://doi.org/10.1016/j.pbb.2008.11.009

Drug Enforcement Administration. (2019). Fentanyl (Trade Names: Actiq ${ }^{\circledR}$, Fentora $^{\mathrm{TM}}$, Duragesic $($ ). $\quad$ Retrieved July $\quad 06, \quad 2020, \quad$ from https://www.deadiversion.usdoj.gov/drug_chem_info/fentanyl.pdf\#search=fentan yl

Drug Enforcement Administration. (2020). Controlled Substance Schedules. Retrieved July 06, 2020, from https://www.deadiversion.usdoj.gov/schedules/

El-Karamany, M. (2017). Case study and review article: epilepsy-like movements induced by fentanyl analgesia [Case Report]. The Egyptian Journal of Internal Medicine, 29(2), 86-90. https://doi.org/10.4103/ejim.ejim_17_17

Ellis, C. R., Kruhlak, N. L., Kim, M. T., Hawkins, E. G., \& Stavitskaya, L. (2018). Predicting opioid receptor binding affinity of pharmacologically unclassified 
designer substances using molecular docking. PloS one, 13(5), e0197734e0197734. https://doi.org/10.1371/journal.pone.0197734

Epstein, D. H., \& Preston, K. L. (2003). The reinstatement model and relapse prevention: a clinical perspective. Psychopharmacology, 168(1-2), 31-41. https://doi.org/10.1007/s00213-003-1470-6

Epstein, D. H., Willner-Reid, J., Vahabzadeh, M., Mezghanni, M., Lin, J.-L., \& Preston, K. L. (2009). Real-time electronic diary reports of cue exposure and mood in the hours before cocaine and heroin craving and use. Archives of general psychiatry, 66(1), 88-94. https://doi.org/10.1001/archgenpsychiatry.2008.509

Fattore, L., Spano, M., Melis, V., Fadda, P., \& Fratta, W. (2011). Differential effect of opioid and cannabinoid receptor blockade on heroin-seeking reinstatement and cannabinoid substitution in heroin-abstinent rats. British journal of pharmacology, 163(7), 1550-1562. https://doi.org/10.1111/j.1476-5381.2011.01459.x

Feltenstein, M. W., \& See, R. E. (2006). Potentiation of cue-induced reinstatement of cocaine-seeking in rats by the anxiogenic drug yohimbine. Behav Brain Res, 174(1), 1-8. https://doi.org/10.1016/j.bbr.2006.06.039

Feltenstein, M. W., Ghee, S. M., \& See, R. E. (2012). Nicotine self-administration and reinstatement of nicotine-seeking in male and female rats. Drug and Alcohol Dependence, 121(3), 240-246. https://doi.org/10.1016/j.drugalcdep.2011.09.001

Fields, H. L., \& Margolis, E. B. (2015). Understanding opioid reward. Trends Neurosci, 38(4), 217-225. https://doi.org/10.1016/j.tins.2015.01.002

Fischer, B., Jones, W., Tyndall, M., \& Kurdyak, P. (2020). Correlations between opioid mortality increases related to illicit/synthetic opioids and reductions of medical 
opioid dispensing - exploratory analyses from Canada. BMC public health, 20(1), 143. https://doi.org/10.1186/s12889-020-8205-z

Fox, H. C., Morgan, P. T., \& Sinha, R. (2014, May). Sex differences in guanfacine effects on drug craving and stress arousal in cocaine-dependent individuals. Neuropsychopharmacology, 39(6), 1527-1537. https://doi.org/10.1038/npp.2014.1

Fragale, J. E., James, M. H., \& Aston-Jones, G. (2020). Intermittent self-administration of fentanyl induces a multifaceted addiction state associated with persistent changes in the orexin system. bioRxiv, 2020.2004.2023.055848. https://doi.org/10.1101/2020.04.23.055848

Frick, K. M. (2020). Estrogens and memory: Basic research and clinical implications. Oxford University Press, New York, New York

Froehlich, J. C. (1997). Opioid peptides. Alcohol health and research world, 21(2), 132136. https://pubmed.ncbi.nlm.nih.gov/15704349

Fu, Y., Matta, S. G., Valentine, J. D., \& Sharp, B. M. (1997). Adrenocorticotropin Response and Nicotine-Induced Norepinephrine Secretion in the Rat Paraventricular Nucleus Are Mediated through Brainstem Receptors*. Endocrinology, 138(5), 1935-1943. https://doi.org/10.1210/endo.138.5.5122

Galaj, E., Manuszak, M., Babic, S., Ananthan, S., \& Ranaldi, R. (2015). The selective dopamine D3 receptor antagonist, SR 21502, reduces cue-induced reinstatement of heroin seeking and heroin conditioned place preference in rats. Drug and Alcohol Dependence, 156, 228-233. https://doi.org/10.1016/j.drugalcdep.2015.09.011

Gallop, R. J., Crits-Christoph, P., Ten Have, T. R., Barber, J. P., Frank, A., Griffin, M. L., \& Thase, M. E. (2007). Differential transitions between cocaine use and abstinence 
for men and women. Journal of Consulting and Clinical Psychology, 75(1), 95103. https://doi.org/10.1037/0022-006X.75.1.95

Gardner, E. L. (2008). Use of animal models to develop antiaddiction medications. Current psychiatry reports, 10(5), 377-384. https://doi.org/10.1007/s11920-008-0061-y

Grau-López, L., Roncero, C., Daigre, C., Gonzalvo, B., Bachiller, D., Rodriguez-Cintas, L., Egido, Á., \& Casas, M. (2012). [Risk factors for relapse in drug-dependent patients after hospital detoxification]. Adicciones, 24(2), 115-122. https://doi.org/10.20882/adicciones.103

Greenwald, M. K., Lundahl, L. H., \& Steinmiller, C. L. (2013). Yohimbine increases opioid-seeking behavior in heroin-dependent, buprenorphine-maintained individuals. $\quad$ Psychopharmacology, 225(4), 811-824. https://doi.org/10.1007/s00213-012-2868-9

Harrison, C., Smart, D., \& Lambert, D. G. (1998). Stimulatory effects of opioids. BJA: British Journal of Anaesthesia, 81(1), 20-28. https://doi.org/10.1093/bja/81.1.20

Haufroid, V., \& Hantson, P. (2015). CYP2D6 genetic polymorphisms and their relevance for poisoning due to amfetamines, opioid analgesics and antidepressants. Clin Toxicol (Phila), 53(6), 501-510. https://doi.org/10.3109/15563650.2015.1049355

Heesch, C. M., Negus, B. H., Keffer, J. H., Snyder, R. W., 2nd, Risser, R. C., \& Eichhorn, E. J. (1995). Effects of cocaine on cortisol secretion in humans. Am J Med Sci, 310(2), 61-64. https://doi.org/10.1097/00000441-199508000-00004

Henthorn, T. K., Liu, Y., Mahapatro, M., \& Ng, K. Y. (1999). Active transport of fentanyl by the blood-brain barrier. J Pharmacol Exp Ther, 289(2), 1084-1089. 
Hitschfeld, M. J., Schneekloth, T. D., Ebbert, J. O., Hall-Flavin, D. K., Karpyak, V. M., Abulseoud, O. A., Patten, C. A., Geske, J. R., \& Frye, M. A. (2015). Female smokers have the highest alcohol craving in a residential alcoholism treatment cohort. Drug Alcohol Depend, 150, 179-182. https://doi.org/10.1016/j.drugalcdep.2015.02.016 J Neurosci, 24(47), 1072610730. https://doi.org/10.1523/jneurosci.3207-04.2004

Hu, M., Crombag, H. S., Robinson, T. E., \& Becker, J. B. (2004, Jan). Biological basis of sex differences in the propensity to self-administer cocaine.

Neuropsychopharmacology, 29(1), 81-85. https://doi.org/10.1038/sj.npp.1300301

Jackson, L. R., Robinson, T. E., \& Becker, J. B. (2006). Sex differences and hormonal influences on acquisition of cocaine self-administration in rats. Neuropsychopharmacology, 31(1),

$129-138$. https://doi.org/10.1038/sj.npp.1300778

Khaleghzadeh-Ahangar, H., \& Haghparast, A. (2015). Intra-accumbal CB1 receptor blockade reduced extinction and reinstatement of morphine. Physiol Behav, 149, 212-219. https://doi.org/10.1016/j.physbeh.2015.06.005

Kirschbaum, C., Wüst, S., \& Strasburger, C. J. (1992). 'Normal' cigarette smoking increases free cortisol in habitual smokers. Life Sci, 50(6), 435-442. https://doi.org/10.1016/0024-3205(92)90378-3

Klar, S. A., Brodkin, E., Gibson, E., Padhi, S., Predy, C., Green, C. A., \& Lee, V. (2016). Notes from the Field: Furanyl-Fentanyl Overdose Events Caused by Smoking Contaminated Crack Cocaine — British Columbia, Canada, July 15-18, 2016. MMWR Morb Mortal Wkly Rep 2016, 65(37),1015-1016. 
Klimas, J., Gorfinkel, L., Fairbairn, N., Amato, L., Ahamad, K., Nolan, S., Simel, D. L., \& Wood, E. (2019). Strategies to Identify Patient Risks of Prescription Opioid Addiction When Initiating Opioids for Pain: A Systematic Review. JAMA Netw Open, 2(5), e193365. https://doi.org/10.1001/jamanetworkopen.2019.3365

Koob, G. F. (2020). Neurobiology of Opioid Addiction: Opponent Process, Hyperkatifeia, and Negative Reinforcement. Biol Psychiatry, 87(1), 44-53. https://doi.org/10.1016/j.biopsych.2019.05.023

Kreek, M. J., \& Koob, G. F. (1998). Drug dependence: stress and dysregulation of brain reward pathways. Drug Alcohol Depend, 51(1-2), 23-47. https://doi.org/10.1016/s0376-8716(98)00064-7

Lai, M., Chen, W., Zhu, H., Zhou, X., Liu, H., Zhang, F., \& Zhou, W. (2013). Low dose risperidone attenuates cue-induced but not heroin-induced reinstatement of heroin seeking in an animal model of relapse. International Journal of $\begin{array}{lll}\text { Neuropsychopharmacology, } & \text { 16(7), }\end{array}$ https://doi.org/10.1017/s1461145712001563

Le Foll, B., Chakraborty-Chatterjee, M., Lev-Ran, S., Barnes, C., Pushparaj, A., Gamaleddin, I., Yan, Y., Khaled, M., \& Goldberg, S. R. (2012). Varenicline decreases nicotine self-administration and cue-induced reinstatement of nicotineseeking behaviour in rats when a long pretreatment time is used. Int $J$ Neuropsychopharmacol, $\quad$ 15(9), $1265-1274$. https://doi.org/10.1017/s1461145711001398 
Le Merrer, J., Becker, J. A., Befort, K., \& Kieffer, B. L. (2009). Reward processing by the opioid system in the brain. Physiological reviews, 89(4), 1379-1412. https://doi.org/10.1152/physrev.00005.2009

Lê, A. D., Quan, B., Juzytch, W., Fletcher, P. J., Joharchi, N., \& Shaham, Y. (1998). Reinstatement of alcohol-seeking by priming injections of alcohol and exposure to stress in rats. Psychopharmacology, 135(2), 169-174. https://doi.org/10.1007/s002130050498

Lee, B., Tiefenbacher, S., Platt, D. M., \& Spealman, R. D. (2004). Pharmacological Blockade of $\alpha 2$-Adrenoceptors Induces Reinstatement of Cocaine-Seeking Behavior in Squirrel Monkeys. Neuropsychopharmacology, 29(4), 686-693. https://doi.org/10.1038/sj.npp.1300391

Lenoir, M., \& Ahmed, S. H. (2007). Heroin-Induced Reinstatement is Specific to Compulsive Heroin Use and Dissociable from Heroin Reward and Sensitization. Neuropsychopharmacology, $32(3)$, 616-624. https://doi.org/10.1038/sj.npp.1301083

Leri, F., \& Stewart, J. (2001). Drug-induced reinstatement to heroin and cocaine seeking: a rodent model of relapse in polydrug use. Exp Clin Psychopharmacol, 9(3), 297306. https://doi.org/10.1037//1064-1297.9.3.297

Li, C., Staub, D. R., \& Kirby, L. G. (2013). Role of GABAA receptors in dorsal raphe nucleus in stress-induced reinstatement of morphine-conditioned place preference in rats. Psychopharmacology (Berl), 230(4), 537-545. https://doi.org/10.1007/s00213-013-3182-x 
Lichtenberg, N. T., \& Wassum, K. M. (2017). Amygdala mu-opioid receptors mediate the motivating influence of cue-triggered reward expectations. European Journal of Neuroscience, 45(3), 381-387. https://doi.org/10.1111/ejn.13477

Lueptow, L. M., Fakira, A. K., \& Bobeck, E. N. (2018). The Contribution of the Descending Pain Modulatory Pathway in Opioid Tolerance. Frontiers in neuroscience, 12, 886-886. https://doi.org/10.3389/fnins.2018.00886

Lynch, W. J. (2006). Sex differences in vulnerability to drug self-administration. Exp Clin Psychopharmacol, 14(1), 34-41. https://doi.org/10.1037/1064-1297.14.1.34

Lynch, W. J., \& Carroll, M. E. (1999). Sex differences in the acquisition of intravenously self-administered cocaine and heroin in rats. Psychopharmacology (Berl), 144(1), 77-82. https://doi.org/10.1007/s002130050979

Lynch, W. J., Roth, M. E., \& Carroll, M. E. (2002). Biological basis of sex differences in drug abuse: preclinical and clinical studies. Psychopharmacology (Berl), 164(2), 121-137. https://doi.org/10.1007/s00213-002-1183-2

Ma, Y.-Y., Chu, N.-N., Guo, C.-Y., Han, J.-S., \& Cui, C.-L. (2007). NR2B-containing NMDA receptor is required for morphine-but not stress-induced reinstatement. Experimental Neurology, 203(2), 309-319. https://doi.org/https://doi.org/10.1016/j.expneurol.2006.08.014

Manchikanti, L., Giordano, J., Boswell, M. V., Fellows, B., Manchukonda, R., \& Pampati, V. (2007). Psychological factors as predictors of opioid abuse and illicit drug use in chronic pain patients. $J$ Opioid Manag, 3(2), 89-100. https://doi.org/10.5055/jom.2007.0045 
Mandt, B. H., Copenhagen, L. I., Zahniser, N. R., \& Allen, R. M. (2015). Escalation of cocaine consumption in short and long access self-administration procedures. Drug alcohol Dependence, $\quad 149, \quad$ 166-172. https://doi.org/10.1016/j.drugalcdep.2015.01.039

Mantsch, J. R., Baker, D. A., Funk, D., Lê, A. D., \& Shaham, Y. (2016). Stress-Induced Reinstatement of Drug Seeking: 20 Years of Progress. Neuropsychopharmacology, 41(1), 335-356. https://doi.org/10.1038/npp.2015.142

Mantsch, J. R., Vranjkovic, O., Twining, R. C., Gasser, P. J., McReynolds, J. R., \& Blacktop, J. M. (2014). Neurobiological mechanisms that contribute to stressrelated cocaine use. Neuropharmacology, $\begin{array}{lllll}76 & \text { Pt } & B\left(\begin{array}{ll}0 & 0\end{array}\right), & 383-394 .\end{array}$ https://doi.org/10.1016/j.neuropharm.2013.07.021

Mantsch, J. R., Yuferov, V., Mathieu-Kia, A. M., Ho, A., \& Kreek, M. J. (2004). Effects of extended access to high versus low cocaine doses on self-administration, cocaine-induced reinstatement and brain mRNA levels in rats. Psychopharmacology (Berl), 175(1), 26-36. https://doi.org/10.1007/s00213-004$1778-\mathrm{x}$

Manubay, J. M., Davidson, J. W., Vosburg, S. K., Jones, J. D., Cooper, Z. D., Fogel, J., Comer, S. D., \& Sullivan, M. A. (2014). Sex differences among opioid-abusing chronic pain patients in a clinical trial. Drug and Alcohol Dependence, 140.

Marchant, N. J., Kaganovsky, K., Shaham, Y., \& Bossert, J. M. (2015). Role of corticostriatal circuits in context-induced reinstatement of drug seeking. Brain research, 1628(Pt A), 219-232. https://doi.org/10.1016/j.brainres.2014.09.004 
Marlatt, G. A. (1996). Models of relapse and relapse prevention: A commentary.

Experimental and Clinical Psychopharmacology, 4(1), 55-60. https://doi.org/10.1037/1064-1297.4.1.55

Matta, S. G., Singh, J., \& Sharp, B. M. (1990). Catecholamines Mediate Nicotine-Induced Adrenocorticotropin Secretion via a-Adrenergic Receptors*. Endocrinology, 127(4), 1646-1655. https://doi.org/10.1210/endo-127-4-1646

Matthes, H. W., Maldonado, R., Simonin, F., Valverde, O., Slowe, S., Kitchen, I., Befort, K., Dierich, A., Le Meur, M., Dollé, P., Tzavara, E., Hanoune, J., Roques, B. P., \& Kieffer, B. L. (1996). Loss of morphine-induced analgesia, reward effect and withdrawal symptoms in mice lacking the mu-opioid-receptor gene. Nature, 383(6603), 819-823. https://doi.org/10.1038/383819a0

McCarberg, B. (2015). The continued rise of opioid misuse: Opioid use disorder. Am J Manag Care, 21, S169-S176.

McNally, G. P. (2014). Extinction of drug seeking: Neural circuits and approaches to augmentation. Neuropharmacology, $\quad 76 \quad P t \quad B, \quad 528-532$. https://doi.org/10.1016/j.neuropharm.2013.06.007

McNally, G., \& Akil, H. (2002). Opioid peptides and their receptors: Overview and function pain modulation. Opioid Peptides Pain Modulation., 1-13.

Mendelson, J. H., Ogata, M., \& Mello, N. K. (1971). Adrenal function and alcoholism. I. Serum cortisol. Psychosomatic medicine, 33 2, 145-157.

Merriam-Webster. (n.d.). Opioid. In Merriam-Webster.com dictionary. Retrieved June 23, 2020, from https://www.merriam-webster.com/dictionary/opioid 
Montandon, G., Qin, W., Liu, H., Ren, J., Greer, J. J., \& Horner, R. L. (2011). PreBotzinger complex neurokinin-1 receptor-expressing neurons mediate opioid-induced respiratory depression. $J$ Neurosci, 31(4), 1292-1301. https://doi.org/10.1523/jneurosci.4611-10.2011

Morgan, A. D., Campbell, U. C., Fons, R. D., \& Carroll, M. E. (2002). Effects of agmatine on the escalation of intravenous cocaine and fentanyl self-administration in rats. Pharmacol Biochem Behav, 72(4), 873-880. https://doi.org/10.1016/s00913057(02)00774-8

Navarro-Zaragoza, J., Núñez, C., Ruiz-Medina, J., Laorden, M. L., Valverde, O., \& Milanés, M. V. (2011). $\mathrm{CRF}_{2}$ mediates the increased noradrenergic activity in the hypothalamic paraventricular nucleus and the negative state of morphine withdrawal in rats. British journal of pharmacology, 162(4), 851-862. https://doi.org/10.1111/j.1476-5381.2010.01090.x

Okada, S., Shimizu, T., \& Yokotani, K. (2003). Extrahypothalamic corticotropin-releasing hormone mediates (-)-nicotine-induced elevation of plasma corticosterone in rats. European Journal of Pharmacology, 473(2), 217-223. https://doi.org/https://doi.org/10.1016/S0014-2999(03)01966-6

Pardridge, W. M. (2015). Transport of Protein and Antibody Therapeutics Across the Blood-Brain Barrier. In Blood-Brain Barrier in Drug Discovery (pp. 146-166). https://doi.org/10.1002/9781118788523.ch8

Pathan, H., \& Williams, J. (2012). Basic opioid pharmacology: an update. British journal of pain, 6(1), 11-16. https://doi.org/10.1177/2049463712438493 
Pradhan, A. A., Befort, K., Nozaki, C., Gavériaux-Ruff, C., \& Kieffer, B. L. (2011). The delta opioid receptor: an evolving target for the treatment of brain disorders. Trends in pharmacological sciences, $\quad 32(10), \quad 581-590$. https://doi.org/10.1016/j.tips.2011.06.008

Ramirez, J.-M. (2010). The human pre-Bötzinger complex identified. Brain, 134(1), 810. https://doi.org/10.1093/brain/awq357

Reichel, C. M., \& Bevins, R. A. (2009). Forced abstinence model of relapse to study pharmacological treatments of substance use disorder. Current drug abuse reviews, 2(2), 184-194. https://doi.org/10.2174/1874473710902020184

Reiner, D. J., Fredriksson, I., Lofaro, O. M., Bossert, J. M., \& Shaham, Y. (2019, 2019/02/01). Relapse to opioid seeking in rat models: behavior, pharmacology and circuits. Neuropsychopharmacology, 44(3), 465-477. https://doi.org/10.1038/s41386-018-0234-2

Ribeiro Do Couto, B., Aguilar, M. A., Manzanedo, C., Rodríguez-Arias, M., Armario, A., \& Miñarro, J. (2006, May). Social stress is as effective as physical stress in reinstating morphine-induced place preference in mice. Psychopharmacology (Berl), 185(4), 459-470. https://doi.org/10.1007/s00213-006-0345-z

Robbins, S. J., Ehrman, R. N., Childress, A. R., \& O'Brien, C. P. (1999). Comparing levels of cocaine cue reactivity in male and female outpatients. Drug Alcohol Depend, 53(3), 223-230. https://doi.org/10.1016/s0376-8716(98)00135-5

Rogers, J. L., Ghee, S., \& See, R. E. (2008). The neural circuitry underlying reinstatement of heroin-seeking behavior in an animal model of relapse. Neuroscience, 151(2), 579-588. https://doi.org/10.1016/j.neuroscience.2007.10.012 
Roth, M. E., \& Carroll, M. E. (2004). Sex differences in the escalation of intravenous cocaine intake following long- or short-access to cocaine self-administration. Pharmacol Biochem Behav, 78(2), 199-207. https://doi.org/10.1016/j.pbb.2004.03.018

Rubio, F. J., Quintana-Feliciano, R., Warren, B. L., Li, X., Witonsky, K. F. R., Valle, F. S. D., Selvam, P. V., Caprioli, D., Venniro, M., Bossert, J. M., Shaham, Y., \& Hope, B. T. (2019). Prelimbic cortex is a common brain area activated during cue-induced reinstatement of cocaine and heroin seeking in a polydrug selfadministration rat model. Eur J Neurosci, 49(2), 165-178. https://doi.org/10.1111/ejn.14203

Rudd, R. A., Paulozzi, L. J., Bauer, M. J., Burleson, R. W., Calson, R. E., Dao, D., . . . Zehner, A. M. (2014). Increases in Heroin Overdose Deaths — 28 States, 2010 to 2012. Morbidity and Mortality Weekly Report, 63(39), 849-854. Retrieved July 7, 2020, from https://www.cdc.gov/mmwr/preview/mmwrhtml/mm6339a1.htm

Rutgers. (2018). Center for Health, Identity, Behavior \&amp; Prevention Studies. Retrieved June 29, 2020, from https://sph.rutgers.edu/centers/chibps/heroin.html Salvatore, M., Wiersielis, K. R., Luz, S., Waxler, D. E., Bhatnagar, S., \& Bangasser, D. A. (2018). Sex differences in circuits activated by corticotropin releasing factor in rats. Hormones and behavior, 97, 145-153. https://doi.org/10.1016/j.yhbeh.2017.10.004

Schluger, J. H., Bart, G., Green, M., Ho, A., \& Kreek, M. J. (2003). Corticotropin-releasing factor testing reveals a dose-dependent difference in methadone maintained vs control subjects. Neuropsychopharmacology, 28(5), 985-994. https://doi.org/10.1038/sj.npp.1300156 
Scholl, L., Seth, P., Kariisa, M., Wilson, N., \& Baldwin, G. (2019). Drug and OpioidInvolved Overdose Deaths - United States, 2013-2017. MMWR Morb Mortal Wkly Rep 2019;67:1419-1427. http://dx.doi.org/10.15585/mmwr.mm675152e1

Schroeder, J. P., Spanos, M., Stevenson, J. R., Besheer, J., Salling, M., \& Hodge, C. W. (2008). Cue-induced reinstatement of alcohol-seeking behavior is associated with increased ERK1/2 phosphorylation in specific limbic brain regions: blockade by the mGluR5 antagonist MPEP. Neuropharmacology, 55(4), 546-554. https://doi.org/10.1016/j.neuropharm.2008.06.057

See, R. E., \& Waters, R. P. (2011). Pharmacologically-induced stress: a cross-species probe for translational research in drug addiction and relapse. American Journal of Translational Research, 3(1), 81-89. https://pubmed.ncbi.nlm.nih.gov/21139808

Serdarevic, M., Striley, C. W., \& Cottler, L. B. (2017). Sex differences in prescription opioid use. Current opinion in psychiatry, 30(4), 238-246. https://doi.org/10.1097/YCO.0000000000000337

Shah, M., \& Huecker, M. R. (2020). Opioid Withdrawal. In StatPearls. StatPearls Publishing.

Shaham, Y., \& Nair, S. G. (2010). Discrete-Cue-Induced Reinstatement. In I. P. Stolerman (Ed.), Encyclopedia of Psychopharmacology (pp. 405-405). Springer Berlin Heidelberg. https://doi.org/10.1007/978-3-540-68706-1_841

Shaham, Y., \& Stewart, J. (1995). Stress reinstates heroin-seeking in drug-free animals: An effect mimicking heroin, not withdrawal. Psychopharmacology, 119(3), 334341. https://doi.org/10.1007/BF02246300 
Shaham, Y., Funk, D., Erb, S., Brown, T. J., Walker, C. D., \& Stewart, J. (1997). Corticotropin-releasing factor, but not corticosterone, is involved in stress-induced relapse to heroin-seeking in rats. The Journal of neuroscience : the official journal of the Society for Neuroscience, 17(7), 2605-2614. https://doi.org/10.1523/JNEUROSCI.17-07-02605.1997

Shaham, Y., Rodaros, D., \& Stewart, J. (1994). Reinstatement of heroin-reinforced behavior following long-term extinction: implications for the treatment of relapse to drug taking. Behavioural Pharmacology, 5(3). https://journals.lww.com/behaviouralpharm/Fulltext/1994/06000/Reinstatement_o f_heroin_reinforced_behavior.15.aspx

Shalev, U., Grimm, J. W., \& Shaham, Y. (2002). Neurobiology of relapse to heroin and cocaine seeking: a review. Pharmacol Rev, 54(1), 1-42. https://doi.org/10.1124/pr.54.1.1

Shalev, U., Highfield, D., Yap, J., \& Shaham, Y. (2000). Stress and relapse to drug seeking in rats: studies on the generality of the effect. Psychopharmacology (Berl), 150(3), 337-346. https://doi.org/10.1007/s002130000441

Shang, Y., \& Filizola, M. (2015). Opioid receptors: Structural and mechanistic insights into pharmacology and signaling. European Journal of Pharmacology, 763(Pt B), 206-213. https://doi.org/10.1016/j.ejphar.2015.05.012

Sharma, B., Bruner, A., Barnett, G., \& Fishman, M. (2016). Opioid Use Disorders. Child and adolescent psychiatric clinics of North America, 25(3), 473-487. https://doi.org/10.1016/j.chc.2016.03.002 
Shepard, J. D., Bossert, J. M., Liu, S. Y., \& Shaham, Y. (2004). The anxiogenic drug yohimbine reinstates methamphetamine seeking in a rat model of drug relapse. Biol Psychiatry, 55(11), 1082-1089. https://doi.org/10.1016/j.biopsych.2004.02.032

Singer, J. D., \& Willett, J. B. (2003). Applied longitudinal data analysis: Modeling change and event occurrence. Oxford University Press. https://doi.org/10.1093/acprof:oso/9780195152968.001.0001

Smith, H. S. (2009). Opioid metabolism. Mayo Clinic proceedings, 84(7), 613-624. https://doi.org/10.1016/S0025-6196(11)60750-7

Smith, R. J., \& Aston-Jones, G. (2012). Orexin/hypocretin 1 receptor antagonist reduces heroin self-administration and cue-induced heroin seeking. The European journal of neuroscience, 35(5), 798-804. https://doi.org/10.1111/j.14609568.2012.08013.x

Smyth, B. P., Barry, J., Keenan, E., \& Ducray, K. (2010). Lapse and relapse following inpatient treatment of opiate dependence. Ir Med J, 103(6), 176-179.

Stafford, N. P., Kazan, T. N., Donovan, C. M., Hart, E. E., Drugan, R. C., \& Charntikov, S. (2019). Individual Vulnerability to Stress Is Associated with Increased Demand for Intravenous Heroin Self-administration in Rats [Original Research]. Frontiers in Behavioral Neuroscience, 13(134). https://doi.org/10.3389/fnbeh.2019.00134

Stahl, S. M. (2008). Stahl's essential psychopharmacology: Neuroscientific basis and practical applications. Cambridge: Cambridge University Press.

Stairs, D. J., Klein, E. D., \& Bardo, M. T. (2006). Effects of environmental enrichment on extinction and reinstatement of amphetamine self-administration and sucrose- 
maintained responding. Behav Pharmacol, 17(7), 597-604. https://doi.org/10.1097/01.fbp.0000236271.72300.0e

Stanley, T. H. (1992). The history and development of the fentanyl series. Journal of Pain and Symptom Management, $\quad 7(3, \quad$ Supplement), S3-S7. https://doi.org/https://doi.org/10.1016/0885-3924(92)90047-L

Stein, C., Schäfer, M., \& Machelska, H. (2003). Attacking pain at its source: new perspectives on opioids. Nat Med, 9(8), 1003-1008. https://doi.org/10.1038/nm908

Stewart, J. (1984). Reinstatement of heroin and cocaine self-administration behavior in the rat by intracerebral application of morphine in the ventral tegmental area. Pharmacol Biochem Behav, 20(6), 917-923. https://doi.org/10.1016/0091$3057(84) 90017-0$

Stine, S. M., Southwick, S. M., Petrakis, I. L., Kosten, T. R., Charney, D. S., \& Krystal, J. H. (2002). Yohimbine-induced withdrawal and anxiety symptoms in opioiddependent patients. Biol Psychiatry, 51(8), 642-651. https://doi.org/10.1016/s00063223(01)01292-6

Sutton, M. A., Karanian, D. A., \& Self, D. W. (2000). Factors that determine a propensity for cocaine-seeking behavior during abstinence in rats. Neuropsychopharmacology, 22(6), 626-641. https://doi.org/10.1016/s0893$133 \times(99) 00160-8$

Thompson, L. L., Claus, E. D., Mikulich-Gilbertson, S. K., Banich, M. T., Crowley, T., Krmpotich, T., Miller, D., \& Tanabe, J. (2012). Negative reinforcement learning is affected in substance dependence. Drug Alcohol Depend, 123(1-3), 84-90. https://doi.org/10.1016/j.drugalcdep.2011.10.017 
Tovar-Díaz, J., Pomrenze, M. B., Kan, R., Pahlavan, B., \& Morikawa, H. (2018). Cooperative CRF and $\alpha 1$ Adrenergic Signaling in the VTA Promotes NMDA Plasticity and Drives Social Stress Enhancement of Cocaine Conditioning. Cell Rep, 22(10), 2756-2766. https://doi.org/10.1016/j.celrep.2018.02.039

Towers, E. B., Tunstall, B. J., McCracken, M. L., Vendruscolo, L. F., \& Koob, G. F. (2019). Male and female mice develop escalation of heroin intake and dependence following extended access. Neuropharmacology, 151, 189-194. https://doi.org/10.1016/j.neuropharm.2019.03.019

Townsend, E. A., Negus, S. S., Caine, S. B., Thomsen, M., \& Banks, M. L. (2019). Sex differences in opioid reinforcement under a fentanyl vs. food choice procedure in rats. Neuropsychopharmacology, $\quad$ 44(12), 2022-2029. https://doi.org/10.1038/s41386-019-0356-1

Trescot, A. M., Datta, S., Lee, M., \& Hansen, H. (2008). Opioid pharmacology. Pain Physician, 11(2 Suppl), S133-153.

University of Arkansas Medical Center. (2020). What is Buprenorphine? Retrieved July 15, 2020, from https://psychiatry.uams.edu/clinical-care/cast-2/buprenorphine/

Vendruscolo, J. C. M., Tunstall, B. J., Carmack, S. A., Schmeichel, B. E., Lowery-Gionta, E. G., Cole, M., George, O., Vandewater, S. A., Taffe, M. A., Koob, G. F., \& Vendruscolo, L. F. (2018). Compulsive-Like Sufentanil Vapor Self-Administration in Rats. Neuropsychopharmacology, 43(4), 801-809. https://doi.org/10.1038/npp.2017.172 
Venniro, M., Caprioli, D., \& Shaham, Y. (2019, Jan). Novel models of drug relapse and craving after voluntary abstinence. Neuropsychopharmacology, 44(1), 234-235. https://doi.org/10.1038/s41386-018-0196-4

Wade, C. L., Vendruscolo, L. F., Schlosburg, J. E., Hernandez, D. O., \& Koob, G. F. (2015). Compulsive-like responding for opioid analgesics in rats with extended access. Neuropsychopharmacology : official publication of the American College of Neuropsychopharmacology, $\quad 40(2), \quad 421-428$. https://doi.org/10.1038/npp.2014.188

Walitzer, K. S., \& Dearing, R. L. (2006). Gender differences in alcohol and substance use relapse. Clin Psychol Rev, 26(2), 128-148. https://doi.org/10.1016/j.cpr.2005.11.003

Wang, S.-C., Chen, Y.-C., Lee, C.-H., \& Cheng, C.-M. (2019). Opioid Addiction, Genetic Susceptibility, and Medical Treatments: A Review. International journal of molecular sciences, 20(17), 4294. https://doi.org/10.3390/ijms20174294

Webster, L. R. (2017). Risk Factors for Opioid-Use Disorder and Overdose. Anesth Analg, 125(5), 1741-1748. https://doi.org/10.1213/ane.0000000000002496

Wee, S., Specio, S., \& Koob, G. (2007). Effects of Dose and Session Duration on Cocaine Self-Administration in Rats. The Journal of pharmacology and experimental therapeutics, 320, 1134-1143. https://doi.org/10.1124/jpet.106.113340

Weiss, V. G., Yates, J. R., Beckmann, J. S., Hammerslag, L. R., \& Bardo, M. T. (2018). Social reinstatement: a rat model of peer-induced relapse. Psychopharmacology (Berl), 235(12), 3391-3400. https://doi.org/10.1007/s00213-018-5048-8 
Wemm, S. E., \& Sinha, R. (2019). Drug-induced stress responses and addiction risk and relapse. Neurobiology of stress, $10, \quad 100148-100148$. https://doi.org/10.1016/j.ynstr.2019.100148

Wolf, M. E. (2012). Chapter 61 - Addiction. In S. T. Brady, G. J. Siegel, R. W. Albers, \& D. L. Price (Eds.), Basic Neurochemistry (Eighth Edition) (pp. 1037-1055). Academic Press. https://doi.org/https://doi.org/10.1016/B978-0-12-3749475.00061-4

Woodcock, E. A., Lundahl, L. H., \& Greenwald, M. K. (2015). Predictors of buprenorphine initial outpatient maintenance and dose taper response among non-treatmentseeking heroin dependent volunteers. Drug and Alcohol Dependence, 146, 89-96. https://doi.org/10.1016/j.drugalcdep.2014.11.016

World Health Organization. (2018). Information sheet on opioid overdose. Retrieved July 06, 2020, from https://www.who.int/substance_abuse/information-sheet/en/

Yan, Y., Yamada, K., Nitta, A., \& Nabeshima, T. (2007). Transient drug-primed but persistent cue-induced reinstatement of extinguished methamphetamine-seeking behavior in mice. Behavioural Brain Research, 177(2), 261-268. https://doi.org/10.1016/j.bbr.2006.11.033

Yue, K., Ma, B., Chen, L., Tian, X., Ru, Q., Gan, Y., Wang, D., Jin, G., \& Li, C. (2014). L-Stepholidine, a naturally occurring dopamine D1 receptor agonist and D2 receptor antagonist, attenuates heroin self-administration and cue-induced reinstatement in rats. Neuroreport, 25(1), 7-11. https://doi.org/10.1097/wnr.0000000000000012 
Zhou, W., Liu, H., Zhang, F., Tang, S., Zhu, H., Lai, M., \& Kalivas, P. W. (2007). Role of acetylcholine transmission in nucleus accumbens and ventral tegmental area in heroin-seeking induced by conditioned cues. Neuroscience, 144(4), 1209-1218. https://doi.org/10.1016/j.neuroscience.2006.11.013 
Samantha Gayle Malone

Degrees Awarded:

East Tennessee State University, B.S. Psychology: Behavioral Neuroscience

Professional Positions:

Teaching Assistant

University of Kentucky, Department of Psychology

2018-2020

Research Assistant

University of Kentucky, Department of Psychology

2018-20120

Graduate Student Advisor, Women in Neuroscience Club

University of Kentucky, Department of Psychology

2020

Graduate Student Congress: Experimental Psychology Representative

University of Kentucky

Scholastic Honors:

Dean's List, ETSU

2014-2017

Dean's Academic Performance Scholarship, ETSU

2014-2017

Tennessee Grocer's Association Scholarship, ETSU

2014-2017

Psychology Honors-In-Discipline Scholarship, ETSU

2017

Spring GSC Travel Award, UKY

2020

Substance Use Priority Research Area Super Students Grant, UKY 2020

NIDA T32 DA035200 Trainee; PI-Dr. Craig Rush, UKY

2020

Publications:

Malone, S.G., Keller, P.S., Hammerslag, L.R., \& Bardo, M.T. (In preparation). Escalation and reinstatement of fentanyl self-administration in male and female rats.

Bardo, M.T., Hammerslag, L.R., \& Malone, S.G. (In preparation). Effect of early life adverse social events on drug abuse vulnerability: Focus on corticotrophinreleasing factor and oxytocin.

Samantha Gayle Malone 